\title{
Research Paper \\ The efficacy of brief cognitive-behavioral therapy in depression, suicidal thoughts and cognitive emotion regulation in women attempting suicide
}

\begin{abstract}
Citation: kiyanzad S, Neshat Doost H.T, Mehrabi H.A, Mousavi S.Gh. The efficacy of brief cognitive-behavioral therapy in depression, suicidal thoughts and cognitive emotion regulation in women attempting suicide. J of Psychological Science. 2021; 20(106): 17671786.
\end{abstract}

Sepideh kiyanzad ${ }^{1}$, Hamid Taher Neshat Doost ${ }^{2}$, Hossein Ali Mehrabi ${ }^{3}$, Seyyed Ghafur Mousavi ${ }^{4}$

1. Ph.D Student, Department of Psychology, Faculty of Education and Psychology, University of Isfahan, Isfahan, Iran.

2. Professor, Department of Psychology, Faculty of Education and Psychology, University of Isfahan, Isfahan, Iran.

3. Assistant Professor, Department of Psychology, Faculty of Education and Psychology, University of Isfahan, Isfahan, Iran.

4. Professor, Department of Psychiatry, Faculty of Medicine, Isfahan University of Medical Sciences, Isfahan, Iran.
URL: https://psychologicalscience.ir/article-1-1208-fa.html
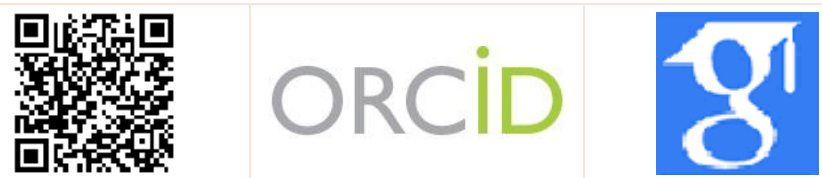

$\underline{10.52547 / J P S .20 .106 .1767}$

\section{A R T I C L E I N F O A B S T R A C T}

Keywords:

Brief cognitive

behavioral therapy,

depression,

suicidal thoughts,

cognitive emotion

regulation
Background: Due to the increasing focus of new therapies on immediate and short-term interventions, brief cognitive-behavioral therapy has been designed with the goal of disabling suicidal mode and stabilizing symptoms by creating self-efficacy in emotion regulation skills and cognitive flexibility. But there is a research gap regarding the possibility of the effectiveness of this treatment in Iranian society.

Aims: This study aimed to determine the efficacy of brief cognitive-behavioral therapy on depression, suicidal thoughts and cognitive emotion regulation in women attempting suicide.

Methods: The present study was a semi-experimental research with a pretest-posttest-follow-up control group design. The statistical population comprised women who attempted suicide in Isfahan in 2020. Thirty patients were selected by purposive sampling method and were randomly assigned to experimental and control groups (15 patients in each group). The research tools include, Beck Depression Inventory-II (1996), Beck Scale for Suicidal Ideation (1979) and Garnefski Cognitive Emotion Regulation Questionnaire (2001), and 12 90-minute sessions brief cognitive-behavioral therapy (Brian \& Rood, 2018). Data analysis was performed by repeated measures analysis of variance.

Results: The findings demonstrate that brief cognitive-behavioral therapy increases adapted emotion regulation strategies and reduces non-adapted strategies, suicidal thoughts and depression at the end of the intervention and follow-up period $(\mathrm{P}<0.01)$.

Conclusion: Brief cognitive-behavioral therapy can reduce depression, suicidal ideation, and nonadapted cognitive emotion regulation strategies in people who attempt suicide.
Received: 09 Apr 2021

Accepted: 06 May 2021 Available: 22 Dec 2021

* Corresponding Author: Hamid Taher Neshat Doost, Professor, Department of Psychology, Faculty of Education and Psychology, University of Isfahan, Isfahan, Iran.

E-mail: h.neshat@edu.ui.ac.ir

Tel: (+98) 9133105922

2476-5740/ (C) 2021 The Authors. This is an open access article under the CC BY-NC-ND license

(https://creativecommons.org/licenses/by-nc/4.0/). 


\section{Monthly Journal of Psychological Science}

\section{Extended Abstract}

\section{Introduction}

According to the National Institute of Mental Health (2019), suicide is a major public health concern in the world. Based on the report by the Centers for Disease Control, the suicide rate among women has increased by $50 \%$ from 2000 to 2016 (O'Brien \& Tomoyasu, 2021).

Suicide is not usually a single event, but rather it is conceptualized as a continuous process of suicidal ideation, a movement towards a suicide plan and preparation, suicide attempt and finally the act of suicide. Thus, reducing suicidal ideation and preventing suicide attempts have been the main goal of increasing the number of psychosocial interventions in recent years (Ong, 2018).

Most studies also suggest that depression has a very high correlation with suicide in terms of rate and is the most common diagnosis in successful suicides (Lew, Huen, Yu, Yuan, Wang, \& Ping, 2019). Thus, in many designed therapies, special focus has been placed on improving the symptoms of depression in these people (Wetherall, Robb \& O'Connor, 2019).

Poor emotion regulation is also considered as a common and interdiagnostic factor that is associated with various forms of psychological pathology, including suicide attempt (Ehring \& Watkins, 2008). Therefore, focusing on cognitive emotion regulation and competencies that can help individuals promote this protective factor will be effective for those who attempt suicide (Hatkevich, Penner \& Sharp, 2019; Raj, 2019).

Considering the increased focus of new therapies on immediate and short-term interventions, brief cognitive-behavioral therapy has been designed with the goal of deactivating suicide mode and stabilizing symptoms by creating self-efficacy in emotion regulation skills and cognitive flexibility. But concerning the effectiveness of this treatment in Iranian society, there is a research gap. Hence, this study aimed to determine the effectiveness of brief cognitive-behavioral therapy in depression, suicidal ideation and cognitive emotion regulation in women attempting suicide.
Vol. 20, No. 106, Winter(January) 2021

\section{Method}

The present research was a quasi-experimental study with a pretest-posttest control group design and a onemonth follow-up. The statistical population included all women attempting suicide who were admitted to Khorshid and Al-Zahra hospitals in Esfahan in summer and autumn of 2020. Considering the loss of subjects, the sample size of the research in each group was considered to be 15 people and the subjects were selected purposefully. The instruments used in this study include the following:

Beck Depression Inventory (BDI-II): This questionnaire is a revised form of the first version of the Depression Inventory (Beck, Steer \& Brown, 1996) and contains 21 items that measure the physical, behavioral and cognitive symptoms of depression. The results obtained by Beck et al. (1996) reported that the internal correlation of this scale, using Cronbach's alpha, was 0.93 and its test-retest reliability was also 0.93 .

Beck Scale for Suicidal Ideation (BSSI): This scale was developed in 1979 by Beck. It is a 19-item selfassessment tool designed to detect and measure the intensity of thoughts, behaviors, and planning for suicide attempt over the past week. Beck reported the reliability coefficient and interrater reliability of this questionnaire to be 0.89 and 0.83 , respectively (Beck \& Steer, 1991).

Cognitive Emotion Regulation Questionnaire (CERQ): This questionnaire is a self-report tool and its 18 -item form was designed by Garnefski and Kraaij (2006) who indicated that the test-retest reliability of strategies is relatively stable and the internal consistency of most of the scales, using Cronbach's alpha coefficients, was confirmed to be 0.80 (Garnefski \& Kraaij, 2006).

In this study, after performing the pretests, brief cognitive-behavioral therapy (Brayan \& Rudd, 2018) was conducted individually for the experimental group during twelve 90-minute sessions in the clinic. The control group did not receive any training during this time (only routine treatments). At the end of the treatment sessions, both groups were post tested and one month later, a follow-up test was administered. Data were analyzed using the latest version of SPSS 


\section{Monthly Journal of Psychological Science}

software and repeated measures analysis of variance and Bonferroni post hoc test.

Reviewing the designed interventions revealed that these studies emphasize increasing protective factors and reducing risk factors, including focusing on enhancing mental health, self-efficacy, emotion control and resistance to psychosocial stress, that moderate suicidal ideation and behavior (Siegmann, Willutzki, Fritsch, Nyhuis \& Teismann, 2019). Therefore, the researcher seeks to evaluate these variables through the mentioned tool in order to determine the effectiveness of cognitive-behavioral therapy.

\section{Results}

Analysis of demographic data demonstrated that the mean age of participants in the brief cognitivebehavioral therapy group and the control group was $28.13 \pm 9.10$ and $28.60 \pm 9.13$, respectively. The highest frequency of education level in the two groups was diploma. $20 \%$ of the brief cognitive-behavioral therapy group and $26.7 \%$ of the control group had the middle school education and others were bachelors, and in terms of marital status, most of the participants in both groups were single.

Based on the descriptive information of the research variables in the three stages of measurement and research groups, there were differences between the mean scores of the research variables of the two groups in the three stages of evaluation. In order to examine the significance of these differences, repeated measures analysis of variance test was used for three stages of evaluation in the brief cognitivebehavioral therapy group and the control group and before performing the test, the assumptions of normal distribution of scores, homogeneity of variances, linearity and sphericity were investigated.

Table 1. Results of repeated measures analysis of variance of the research variables related to in-group and out-group effec

\begin{tabular}{|c|c|c|c|c|c|c|c|c|c|c|}
\hline Title & Variable & Effects & Source & $\begin{array}{l}\text { Sum of } \\
\text { squares }\end{array}$ & $\begin{array}{l}\text { Degree } \\
\text { of } \\
\text { freedom }\end{array}$ & $\begin{array}{l}\text { Mean } \\
\text { square }\end{array}$ & $\underset{\text { statistic }}{\mathrm{F}}$ & $\begin{array}{c}\text { Significance } \\
\text { level }\end{array}$ & $\begin{array}{l}\text { Effect } \\
\text { size }\end{array}$ & $\begin{array}{l}\text { Test } \\
\text { power }\end{array}$ \\
\hline \multirow{12}{*}{ 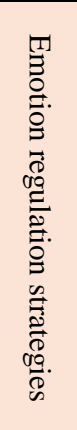 } & \multirow{3}{*}{ Depression } & \multirow{2}{*}{ Within- subject } & Time & 2115.089 & 2 & 1057.544 & 59.391 & $<0.001$ & 0.680 & $\overline{1}$ \\
\hline & & & Interaction & 1519.756 & 2 & 759.878 & 42.657 & $<0.001$ & 0.604 & 1 \\
\hline & & Between-subject & Group & 2141.344 & 1 & 2141.344 & 22.958 & $<0.001$ & 0.451 & 0.996 \\
\hline & \multirow{3}{*}{$\begin{array}{l}\text { Suicidal } \\
\text { ideation }\end{array}$} & \multirow{2}{*}{ Within- subject } & Time & 1444.156 & 1.452 & 994.633 & 85.509 & $<0.001$ & 0.753 & 1 \\
\hline & & & Interaction & 479.622 & 1.452 & 516.287 & 44.386 & $<0.001$ & 0.613 & 1 \\
\hline & & Between-subject & Group & 613.611 & 1 & 613.611 & 19.747 & $<0.001$ & 0.414 & 0.990 \\
\hline & \multirow{3}{*}{ Adaptive } & \multirow{2}{*}{ Within- subject } & Time & 1538.600 & 2 & 769.300 & 91.007 & $<0.001$ & 0.765 & 1 \\
\hline & & & Interaction & 1160.689 & 2 & 580.344 & 68.654 & $<0.001$ & 0.710 & 1 \\
\hline & & Between-subject & Group & 1570.844 & 1 & 1570.844 & 71.999 & $<0.001$ & 0.720 & 1 \\
\hline & \multirow{3}{*}{$\begin{array}{l}\text { Non- } \\
\text { adaptive }\end{array}$} & \multirow{2}{*}{ Within- subject } & Time & 1072.022 & 1.501 & 714.252 & 56.559 & $<0.001$ & 0.669 & 1 \\
\hline & & & Interaction & 885.267 & 1.501 & 589.823 & 46.706 & $<0.001$ & 0.625 & 1 \\
\hline & & Between-subject & Group & 846.400 & 1 & 846.400 & 33.406 & $<0.001$ & 0.544 & 1 \\
\hline
\end{tabular}

According to the results of Table (1), the effect of time is significant and the means of the research variables are different in the three evaluation stages of pretest, posttest and follow-up. Further, there is an interaction between time and group; that is, the means of the research variables in the stages of pretest, posttest and follow-up are different in the cognitivebehavioral therapy group and the control group.

According to Table (2), the pretests of the research variables are not different in the two groups; but the variables have shown a significant group difference in the posttest and follow-up, suggesting that the brief cognitive-behavioral therapy has been effective in the research variables.

Then, the results of Bonferroni test were evaluated to examine the pairwise differences of the evaluation stages in each of the therapy and control groups. The results indicated that in the brief cognitive-behavioral therapy group, there is a significant difference between the pretest and posttest stages and the pretest and follow-up stages in the mean scores of the research variables $(\mathrm{p}<0.01)$. But no difference was reported between the posttest and follow-up stages in the mean scores of the research variables $(p>0.01)$, 
which suggests the persistence of the treatment effect over time.

In the control group, no significant difference was found in the three pairwise comparisons. Comparison of group differences of means of the research variables in each evaluation stage (Table 2) and pairwise comparison of evaluation stages in each research group (Table 3) and review of the means revealed that the brief cognitive-behavioral therapy has reduced depression, suicidal ideation and nonadaptive emotion regulation strategies, and has increased adaptive emotion regulation strategies.

Table 2. Pairwise comparison between the experimental and control groups in each of the evaluation stages

\begin{tabular}{|c|c|c|c|c|c|c|c|c|c|}
\hline \multirow[t]{2}{*}{ Scale } & \multirow[t]{2}{*}{ Variable } & \multirow[t]{2}{*}{ Stage } & \multirow[t]{2}{*}{ Group I } & \multirow[t]{2}{*}{ Group $\mathbf{J}$} & \multirow[t]{2}{*}{$\begin{array}{c}\text { Mean } \\
\text { difference (I-J) }\end{array}$} & \multirow[t]{2}{*}{$\begin{array}{c}\text { Standard } \\
\text { error }\end{array}$} & \multirow[t]{2}{*}{ Sig. } & \multicolumn{2}{|c|}{$\begin{array}{l}95 \% \text { confidence } \\
\text { interval for } \\
\text { differences }\end{array}$} \\
\hline & & & & & & & & Min. & Max. \\
\hline \multirow{12}{*}{ 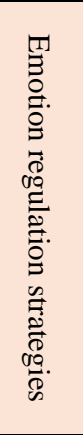 } & \multirow{3}{*}{ Depression } & Pretest & Experimental & Control & 1.867 & 2.574 & 0.474 & -3.407 & 7.140 \\
\hline & & Posttest & Experimental & Control & -15.467 & 2.272 & $<0.001$ & -20.120 & -10.813 \\
\hline & & Follow-up & Experimental & Control & -15.667 & 2.323 & $<0.001$ & -20.425 & -10.908 \\
\hline & \multirow{3}{*}{$\begin{array}{l}\text { Suicidal } \\
\text { ideation }\end{array}$} & Pretest & Experimental & Control & 2.933 & 1.339 & 0.037 & 0.191 & 5.675 \\
\hline & & Posttest & Experimental & Control & -9.600 & 1.523 & $<0.001$ & -12.719 & -6.481 \\
\hline & & Follow-up & Experimental & Control & -9.000 & 1.512 & $<0.001$ & -12.096 & -5.904 \\
\hline & \multirow{3}{*}{ Adaptive } & Pretest & Experimental & Control & -1.800 & 1.270 & 0.167 & -4.401 & 0.801 \\
\hline & & Posttest & Experimental & Control & 13.600 & 1.176 & $<0.001$ & 11.192 & 16.008 \\
\hline & & Follow-up & Experimental & Control & 13.267 & 1.472 & $<0.001$ & 10.250 & 16.283 \\
\hline & \multirow{3}{*}{$\begin{array}{c}\text { Non- } \\
\text { adaptive }\end{array}$} & Pretest & Experimental & Control & 2.733 & 1.688 & 0.117 & -0.724 & 6.190 \\
\hline & & Posttest & Experimental & Control & -10.800 & 1.276 & $<0.001$ & -13.414 & -8.186 \\
\hline & & Follow-up & Experimental & Control & -10.333 & 1.195 & $<0.001$ & -12.782 & -7.884 \\
\hline
\end{tabular}

Note: Non-significant relationships are shaded in the table.

\section{Conclusion}

This study aimed to investigate the effectiveness of brief cognitive-behavioral therapy in depression, suicidal ideation and cognitive emotion regulation in women attempting suicide in Esfahan. The present research demonstrated that this treatment has been effective in reducing the severity of depressive symptoms in these people. The structure of the brief cognitive-behavioral therapy is based on the Fluid Vulnerability Theory (FVT) of suicide, and by focusing on making changes in the cognitive style and creating insight into cognitive biases and understanding the relationship between thoughts, emotions and behaviors, it improves the process of formation of depressive symptoms in the second phase of the treatment. This finding is consistent with the results of the study by Bishop and Pigeon (2021) and Tanaka et al. (2019), who positively assessed the effect of this treatment on depressive symptoms.

The results of this study indicate the effect of this treatment on reduced suicidal ideation. In this model, it is believed that the suicidal belief system indicates the occurrence of psychological vulnerability in two basic mechanisms in suicidal behavior: cognitive inflexibility and deficiency in emotion regulation.
Thus, in the first phase of this treatment, the patient learns how to extract positive emotional states and remembers why he wants to continue his life, and this is achieved through techniques such as reasons to live list, survival kit and mindfulness exercises. This finding is consistent with the results of studies by Sinyor et al. (2020), Lee et al. (2020) and Ecker et al. (2019) regarding the positive effects of this treatment on suicidal ideation.

On the other hand, the findings of this study suggested that the brief cognitive-behavioral therapy is effective in increasing adaptive strategies and reducing non-adaptive strategies in cognitive emotion regulation. In the behavioral domain of suicide, the main risk factors include lack of skills in the areas of distress tolerance and emotion regulation, each of which increases the likelihood of maladaptive coping in response to stressful and provocative situations and in the first phase, this treatment, through trainings such as safety program, relaxation competencies, breathing retraining and mindfulness exercises, directly targets the defects of these competencies; this finding is congruent with the results of studies by Roberge et al. (2019) and Bryan, Peterson and Rudd (2018). Therefore, according to the results of this 


\section{Monthly Journal of}

Psychological_Science

Vol. 20, No. 106, Winter(January) 2021

study, the use of this therapeutic method is recommended to therapists specialized in this field.

\section{Ethical Considerations}

Compliance with ethical guidelines: The authors extracted this article from the $\mathrm{PhD}$ dissertation of the first author, which approved under No IR.UI.REC 1399.011 date, 26.06.2019 in the Faculty of medical sciences, University of Isfahan, Isfahan. The Iranian National Gas Company authorities have signed the permission to carry the research. Ethical considerations like gaining the informed consent of the participants and the confidentiality of responses were considered in this research.
Funding: This study was conducted as a $\mathrm{PhD}$ thesis with no financial support.

Authors' contribution: The first author was the senior author, the second were the supervisors and the third and forth was the advisors.

Conflict of interest: the authors declare no conflict of interest for this study.

Acknowledgments: I would like to appreciate the supervisor, the advisors, the participants, and consultants of this research, as well as the staff of Khorshid and Al-Zahra hospitals who helped in this research. 


\section{اثربخشى درمان شناختى رفتارى مختصر بر افسردكى، افكار خودكشى و تنظيم شناختى هيجان در زنان اقدامكننده به}

\section{خود كشى}

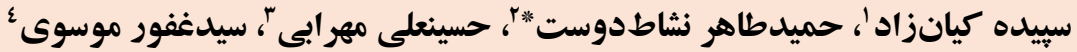

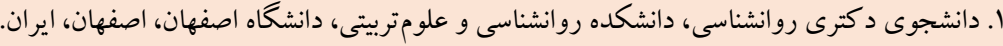

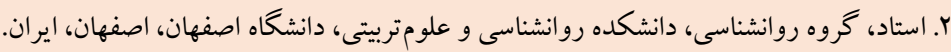

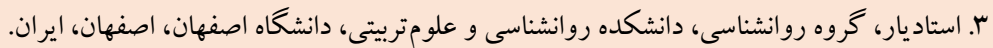

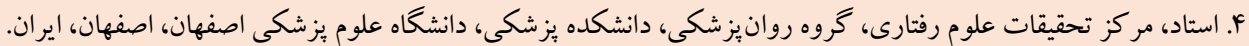

جكيده

زمينه: با توجه به افزايش تمركزدرمانهاى جديد بر مداخلات فورى و كو تاه مدت، درمان شناختى رفتارى مختصر با هدف غيرفعال كردن

حالت خود كشى و تثبيت علائم از طريق ايجاد خود كار آمدى در مهارتهاى تنظيم هيجان و انعطاف يذيرى شناختى طر احى شده است. اما در خصوص احتمال اثربخشى اين درمان درجامعه ايران شكاف تحقيقاتى وجود دارد. هدف: اين مطالعه با هدف تعيين اثربخشى درمان شناختى رفتارى مختصر بر افسردگى إنى افكارخو دوشى و تنظيم شناختى هيجان در زنان اقدام كننده به خود كشى انجام شده است. روش: يزوهش حاضر از نوع نيمه آزمايشى با طرح ييش آزمون - يس آزمون - بيخيرى و گروه گواه بود. جامعه آمارى زنان اقدام كننده به

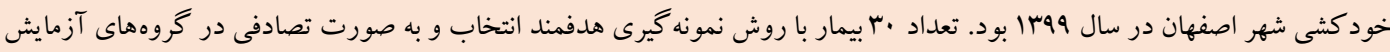

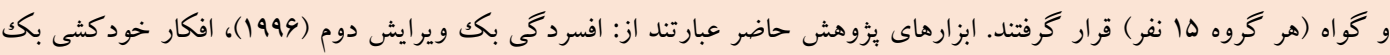

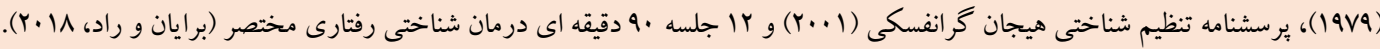

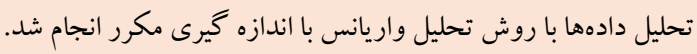
يافته ها: نتايج نشان مىدهد كه درمان شناختى - رفتارى مختصر عامل افزايش راهبردهاى تنظيم هيجانى سازش يافته و كاهش راهب راهبردهاى

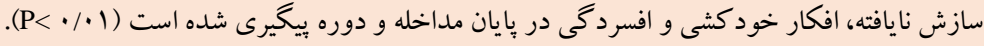
نتيجه گيرى: درمان شناختى رفتارى مختصر مى تواند افسردگى، افكار خود كشى و راهبردهاى سازش نايافته در تنظيم شناختى هيجان را در افراد اقدام كننده به خود كشى كاهش دهد.
مشخصات مقاله

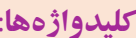
درمان شناختى و رفتارى مختصر،

$$
\text { افسردگ }
$$

|فكارخود كشى،

تنظيم شناختى هيجان

* نويسنده مسئول: حميدطاهر نشاطدوست، استاد، گروه روانشناسى، دانشكده روانشناسى و علوم تربيتى، دانشگاه اصفهان، اصفهان، ايران. 
دهد و بعنوان متغيير شناختى در بيشبينى افكار و رفتار خودكشى نقش

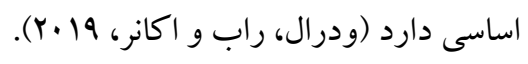

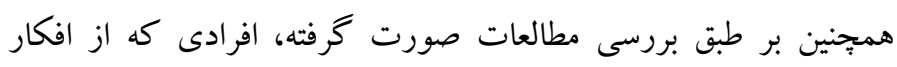

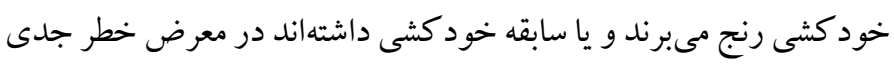

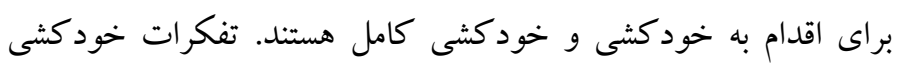

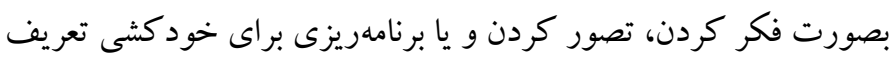
مىشوند، در حالى كه رفتار خودكشى بعنوان تعامل در رفتار بالقوه

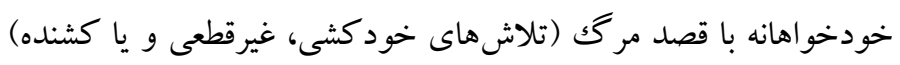

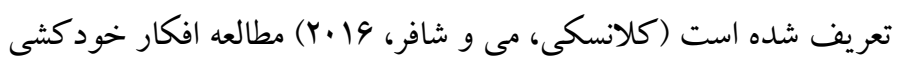

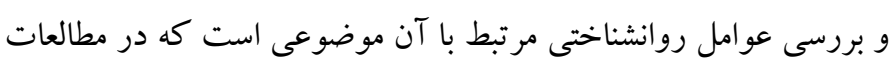

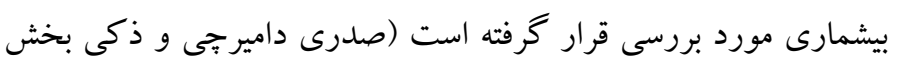

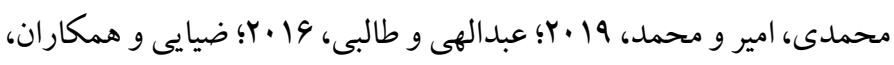

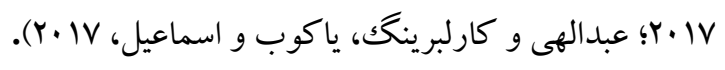

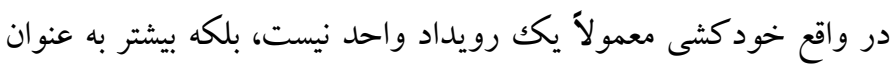

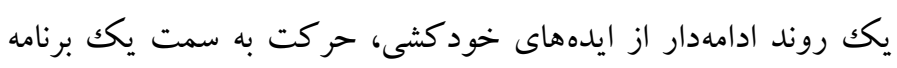

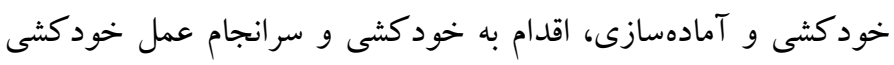

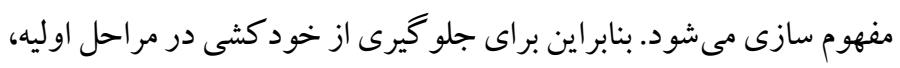

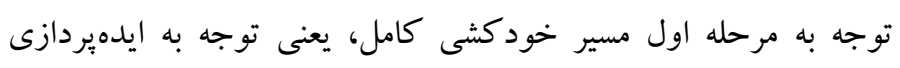

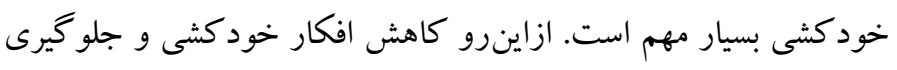

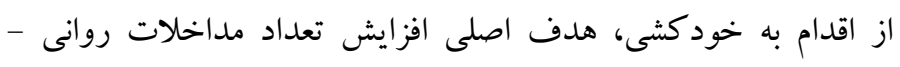

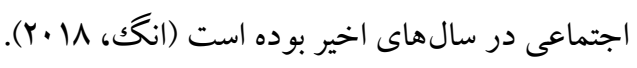
تنظيم هيجان ضعيف نيز بعنوان عاملى مشتر كك و بين تشخيصى در نظر كرفته شده است كه با اشكال مختلف آسيبشناسى روانى، از جمله اقدام

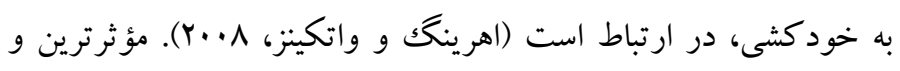
بالاترين سطح تنظيم هيجانى، تنظيم شناختى هيجان است. در تنظيم

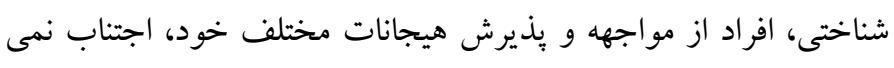

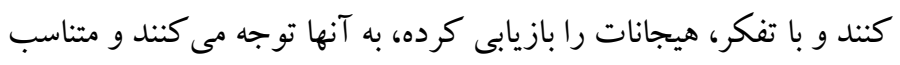
با نيازهاى روانى و شرايط، به تنظيم هيجانات خود مى يردازند. اين سطح از

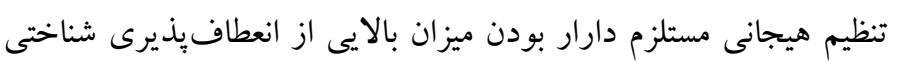

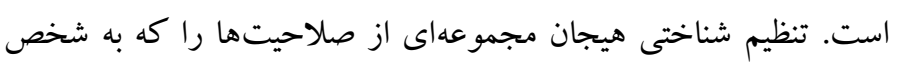

3 . Depression

4. Emotion Regulation
مقلفم

براساس اعلام انستيتوى ملى بهداشتروانى' (Y.19)، خودكشى يكك

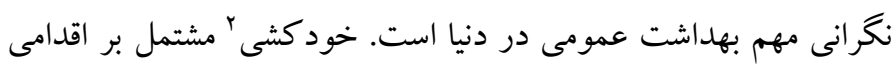

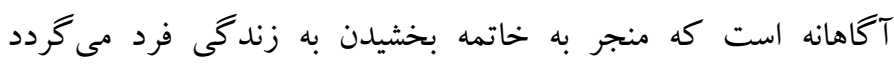

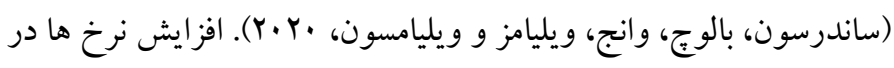

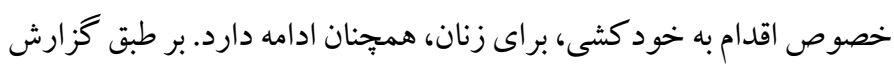

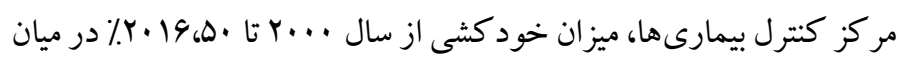

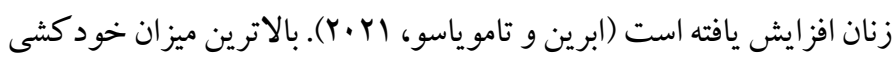

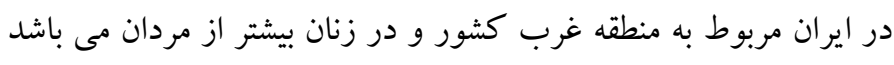

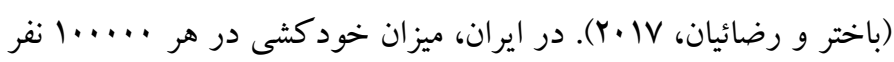

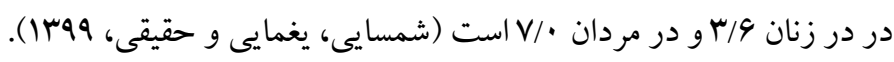
بر طبق يزوهشها، علارغم بالاتر بودن ميزان خود كشى در مردان، زنان

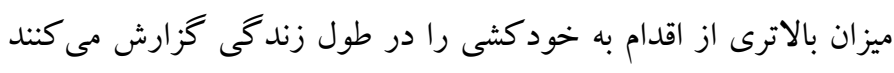

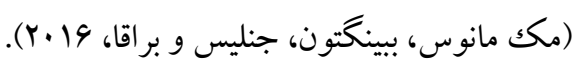

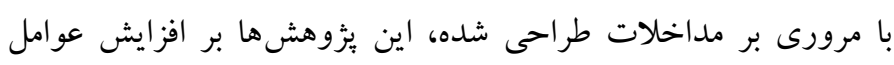

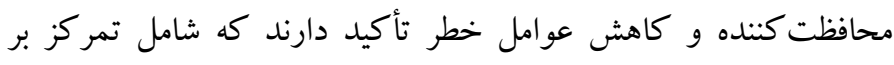
افزايش سلامتروان، خود كار آمدى، مهار هيجان و مقاومت در برابر فشار

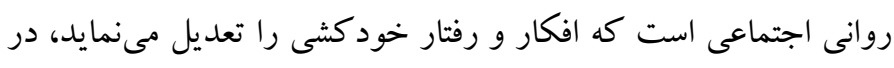

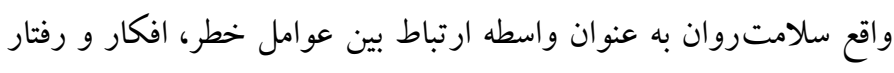

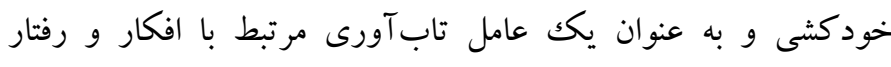

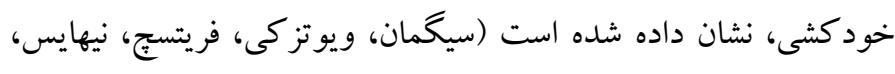

ولتر و تيسمن، (Y) (Y) (

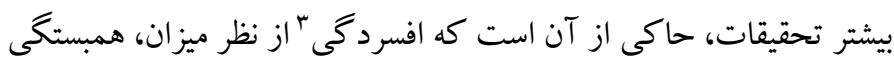

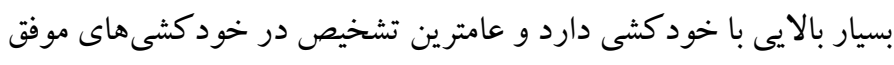

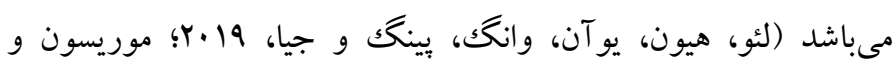

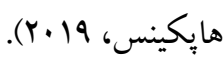
افسرد گى يكك احساس مداوم غم و اندوه و از دست دادن علاقه به جيزهايى

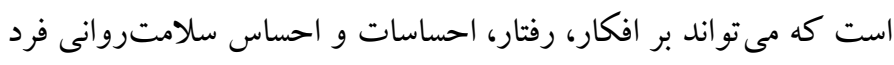

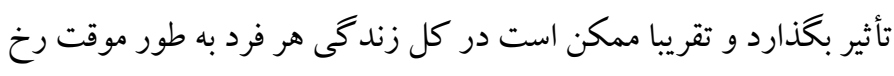

\footnotetext{
1. National Institute of Mental Health
}

${ }^{2}$. Suicide 


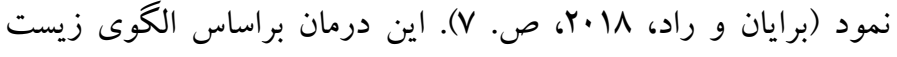

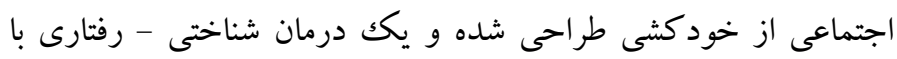

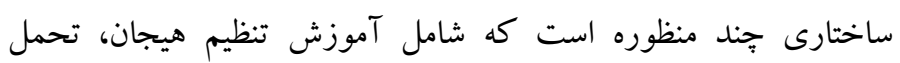

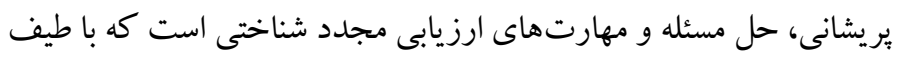
وسيعى از مداخلات شناختى - رفتارى مانند بازسازى شناختى و تمرينهاى

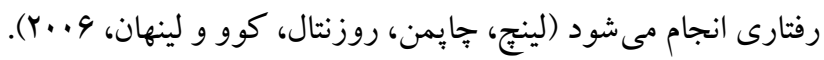

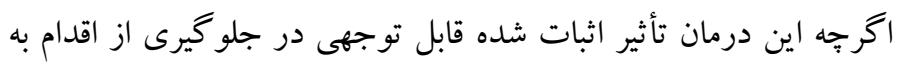

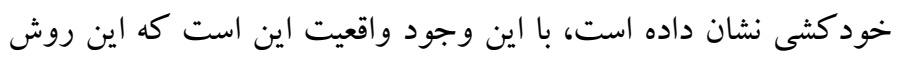
درمانى و بسيارى از روشهاى مؤثر بر خود كشى، بسيار منبع دار، زمان بر دان

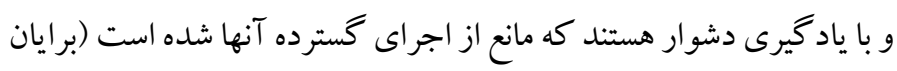

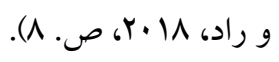

با توجه به هزينههاى درمانى و عدم تمايل افر اد بر درمانهاى طولانى مدت، اخيرا بيشترين تمركز بر درمانهاى كوتاه مدت قرار گرفته است (ين و ورمانو

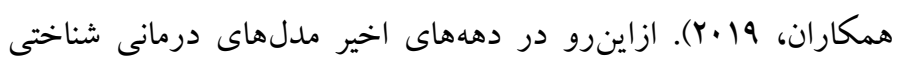
رفتارى مختصر و وييجيدهتر كه مى توانند به صورت عملى تر و انعطاف يذير ارائه شوند، مورد تو جه قرار گر فتهاند.

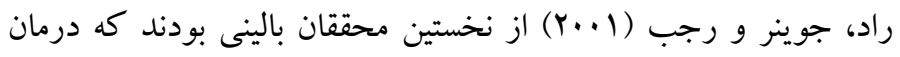
شناختى - رفتارى مختصر را در جهت درمان بيماران خودكشى مطرح

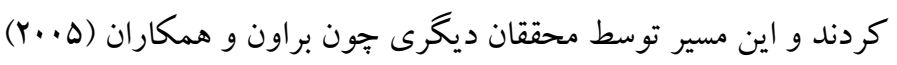
دنبال و در طى يك دهه كذشته بسيار توسعه يافته است (برايان و راد، (1) امروزه درمان شناختى رفتارى مختصر به عنوان "قدم بعدى رو به جلو" در

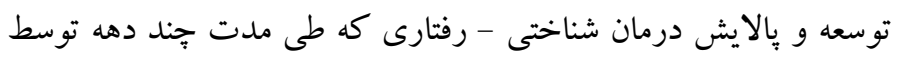

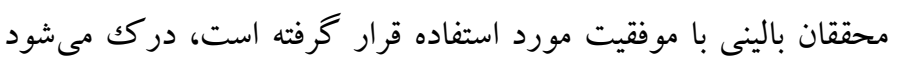

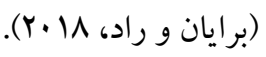

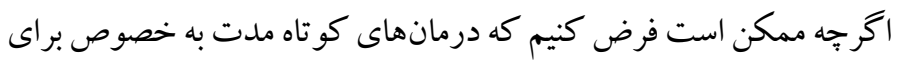
بيماران برخطر خودكشى كه داراى مشكلات بالينى جالش برانگيزيز،

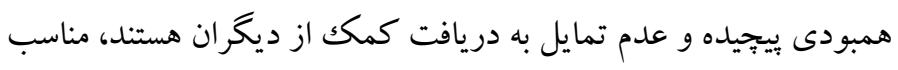
نيست، شواهد تجربى حمايت از اثربخشى درمان شناختى رفتارى مختصر

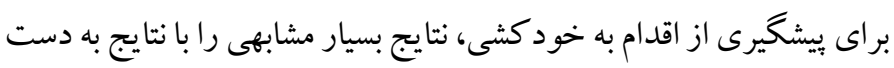

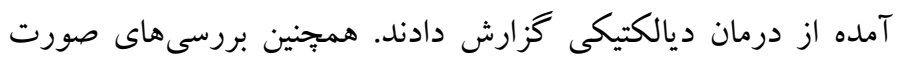

اجازه مى دهد نظارت، ارزيابى و اصلاح فر آيندهاى ايجاد شده در بيدايش احساسات را انجام دهد در بر مى گيرد (لازاريستا و همكار ان، 19 •.Y).

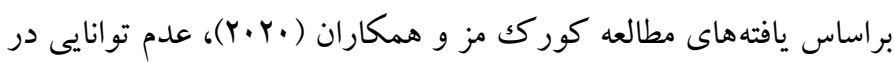

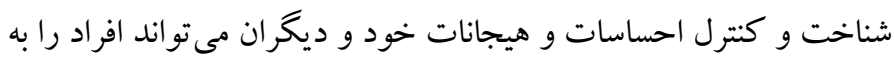
عنوان راهحلى براى مشكلات خود به سمت خودكشى سوق دهد. در

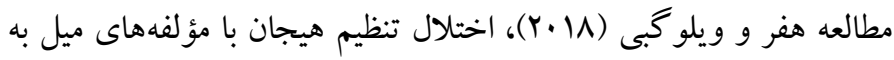

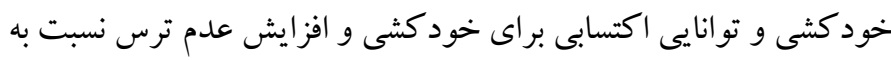

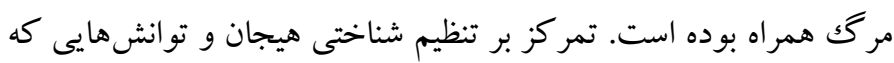

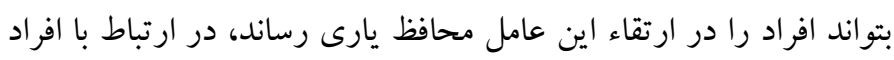

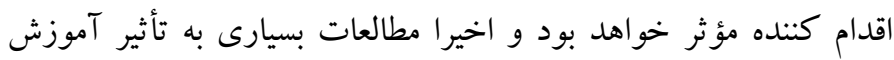
تو انش هاى تنظيم شناختى هيجان در كاهش خود كشى يرداختهاند (آزادى،

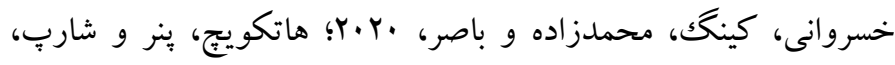

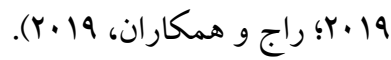
اثربخشى مداخلات ييشخيرى از خود كشى در كاهش ميز ان خود كشى در

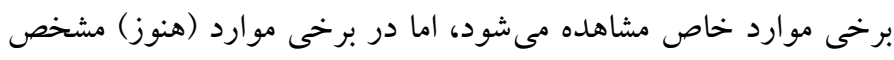

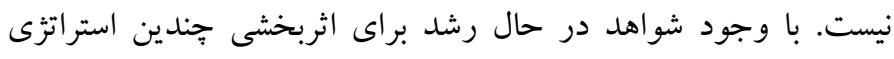

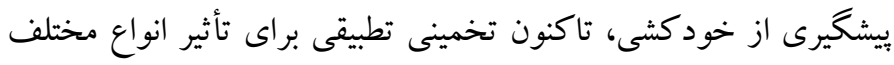

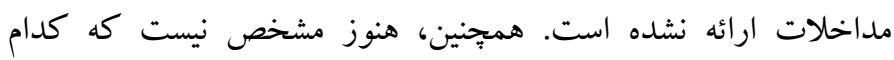
استراتزى مؤثرترين است. استدلال شده است كه مؤثرترين اقدام در جهت

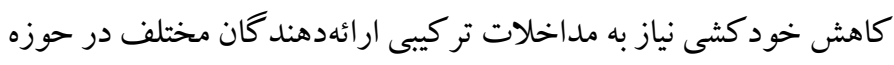
هاى مختلف و به صورت مداخلات به اصطلاح جند سطحى دارد (هافسترا و همكاران، (Y) (Y) (19).

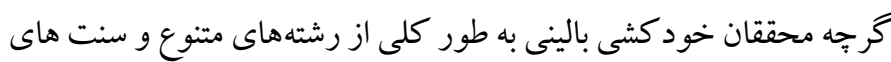

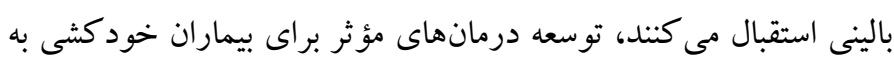

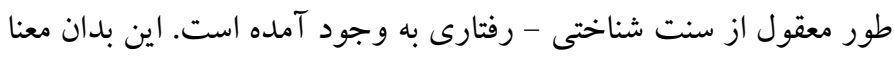
نيست كه محققان بالينى كه در ديدكاهها و سنن نظرى مختلف آموزش

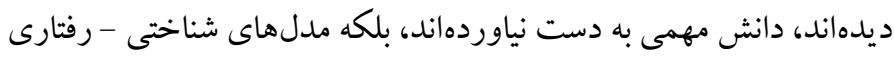

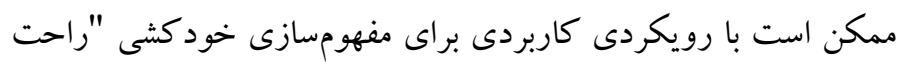

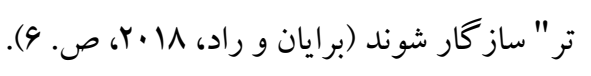

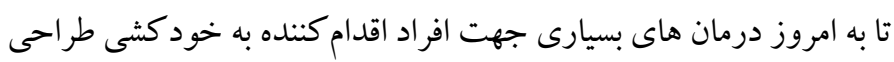
شده است، از موفق ترين اين درمانها مى توان به درمان ديالكتيكى' اشاره

${ }^{1}$. Dialectical Behavior Therapy 
همكاران (Y.IV) در مطالعات خود نشان دادند كه اين درمان منجر به

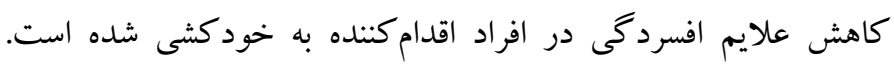

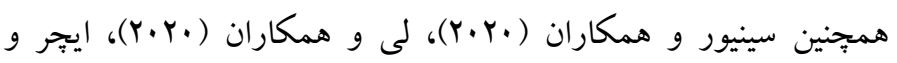

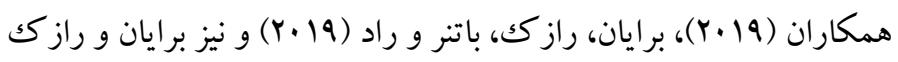

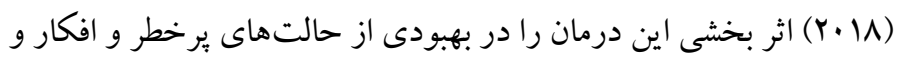
اقدام به خود كشى نشان دادند.

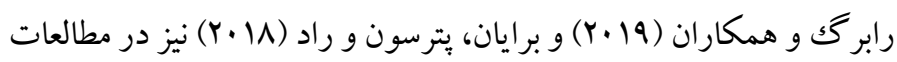
خود به تأثير اين درمان بر روى افزايش راهبردهاى سازشيافئه تنظيم شناختى هيجان اشاره كردند. بر طبق مطالعات صورت گرفته، روزها و هفته ها بلافاصله بس از ترخديص

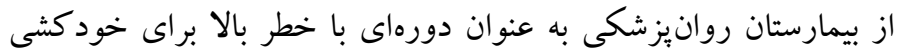
تثبيت شده است (لى، برايان و راد، ·r.r.

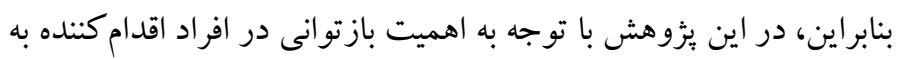

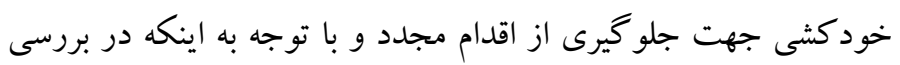
هاى صورت گرفته در خصوص مؤثر بودن اين مداخله شناخته شده درد ايران شكاف تحقيقاتى وجود دارد، بر آن شديم تا تأثير اين درمان را بر بر مان

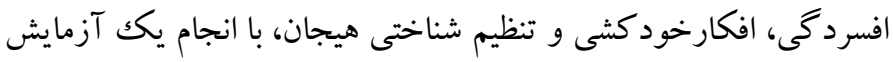
كنترل شده تصادفى از درمان شناختى رفتارى مختصر (BCBT) در زنان اقدام كننده به خود كشى مورد بررسى قرار دهيم.

روش الف) طرح ثئوهش و شر كت كنند كان: روش يزوهش حاضر از نوع شبه

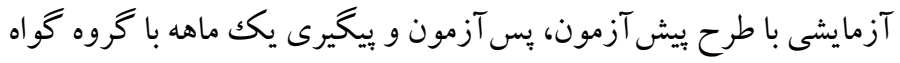

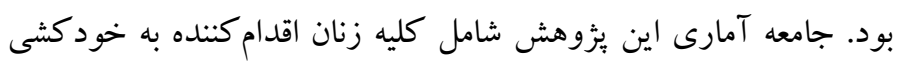

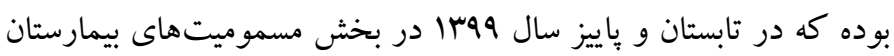
هاى خورشيد و الزهرا در اصفهان بسترى شدند. با توجه به اين كه حجم نمونهُ بيشنهادى در بثزوهش هاى مداخلهاى حداقل

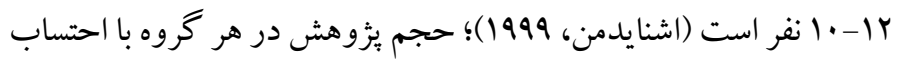
ريزش ها نفر در نظر گرفته شد.
كرفته اوليه نشان داد كه تأثير درمان شناختى رفتارى مختصر كمتر از درمان

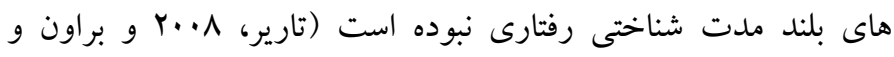

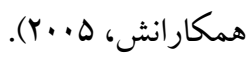
از ميان نسخههاى كو تاه مدت درمان شناختى و رفتارى كه به منظور خاص هاص

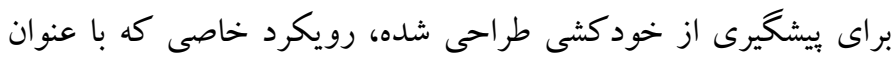

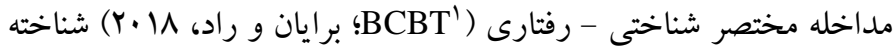

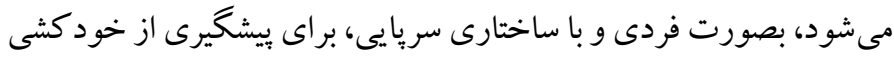

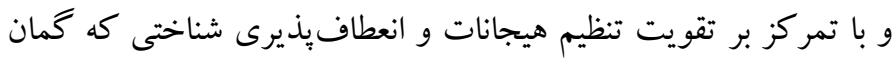

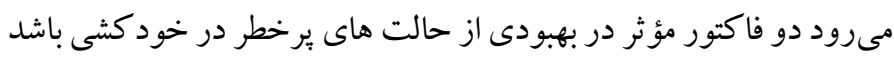
طراحى شده است و يكك روش درمانى مرحله به مرحله براى هدف قرار دادن مستقيم خطر خود كشى مى باشد (روجاس و همكاران، (Y.Y.Y).

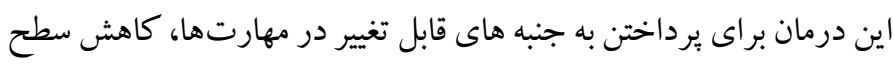

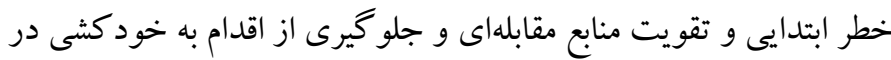
صورت فعال شدن حالت خودكشى طراحى شده است (ديفن باج و و

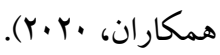
يكك مؤلفه تأثير گذار در اين رويكرد درمانى نسخه اصلاح شده برنامه بِاسخ

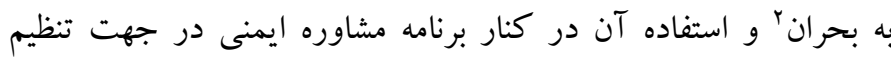

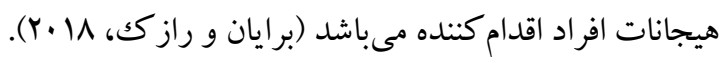

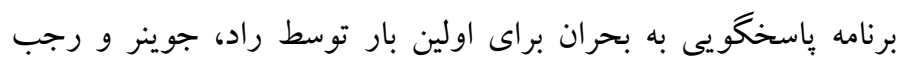

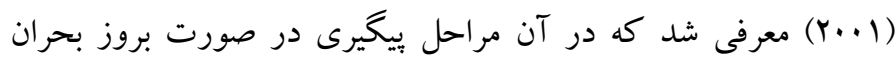
خود كشى را ترسيم مى كند. طرح ياسخ به بحران توسط استنلى و براون

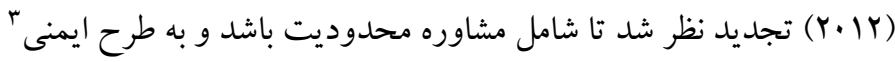
تغيير نام داد (ديفن باج و همكاران، ·r.r. بسيارى از اصلاحات و بِالايشهاى درمان شناختى رفتارى براون و و ودان

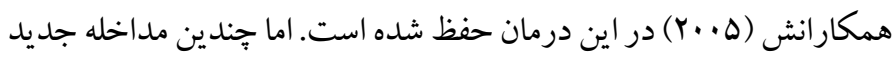
براى اين درمان ايجاد شده است كه مهمترين آنها كيت بقا و اضافه شدن

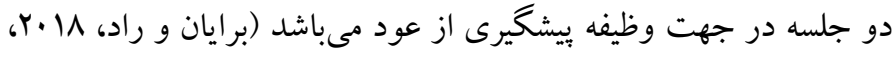
تأثير اين درمان مختصر در مطالعات بسيارى مورد اثبات علمى قرار گر فته

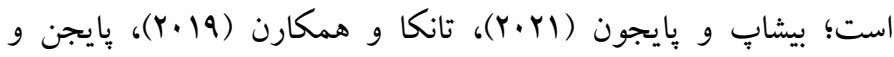

1. Brief Cognitive Behavioral Therapy

${ }^{2}$. Crisis response plan 
ملاككهاى ورود به نمونه عبارت بود از: كزارش افكار خود كشى، داشتن رضايت آكاهانه جهت شركت، مبتلا نبودن همزمان به اختلالات حاد روان يزشكى و جسمانى تأييد شده توسط متخصص، قرار داشتن در گروه سنى

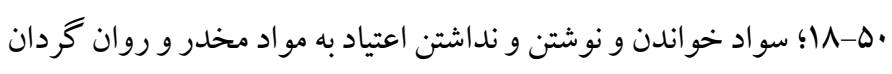

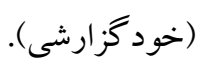

ملاككهاى خروج نيز شامل: شركت همزمان در ساير برنامههاى درمانى، عدم تمايل براى ادامه شركت در بزظوهش و غيبت بيش از دو جلسه بود. در اين يزٔوهش يس از اجراى يِش آزمونها، درمان شناختى و رفتارى

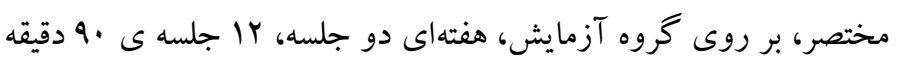
اى به صورت فردى و در كلينيك اجرا شد؛ گروه گواه در اين فاصله آموزشى دريافت نكردند. يس از يّايان جلسات درمانى مجدداً از هر دو كروه يس آزمون و يكك ماه بعد مرحله يبحيرى گر فته شد. دادهها با استفاده از آخرين نسخه نرمافزار SPSS و به روش تحليل واريانس با اندازه گيرى مكرر و آزمون تعقيى بونفرونى تحليل شد. خلاصه جلسات آموزشى بر اساس روش ارائه شده توسط برايان و راد (Y.1N)
آزمودنى ها به صورت هدفمند و بر طبق ملاكك هاى مورد نظراز ميان بيماران انتخاب شدند. يس از ارائه توضيحات لازم در خصوص فر آيند يزوهش، اهداف يثزوهش، تعداد جلسه ها، طول مدت هر جلسه و مسائل مطرح شونده و همجينين دادن اطمينان خاطر در خصوص محرمانه ماندن اطلاعات و يس از جلب رضايت افراد، رضايتنامه كتبى از شركت كنند كان هر دو كروه اخذ شد. افراد شركت كننده، از نظر مشخصات همتا شده و بطور تصادفى در دو كروه آزمايش و كواه (ها نفره) قرار داده شدند. با توجه به اينكه رها كردن افراد با سابقه خود كشى غير اخلاقى مىباشد، لازم به ذكر است كه افر اد گروه گو اه تحت نظر كادر روانيزشكى بيمارستان بوده و خدمات و برنامه ايمنى جهت آكاهسازى افراد و خانواده آنها بصورت روتين در بيمارستان صورت مى گيرد (مداخلات روتين)، اما اين افراد با توجه به ملاكك ورود بزوهش از ميان افرادى انتخاب شدند كه با آكاهى كامل تمايلى به مصرف دارو نداشتهاند، همجينين بعد از اتمام يزوهش از اين افراد جهت شر كت در جلسات آموزشى در صورت تمايل دعوت به عمل آمد. از هر دو گروه يرسشنامههاى مقرر شده، بصورت بيش آزمون بعمل آمد و بعد از انجام مداخله نيز يس آزمون و يّيخيرى (يكك ماه) صورت كرفت.

جدول ا. خلاصه محتواى جلسات آموزشى درمان شناختى رفتارى مختصر

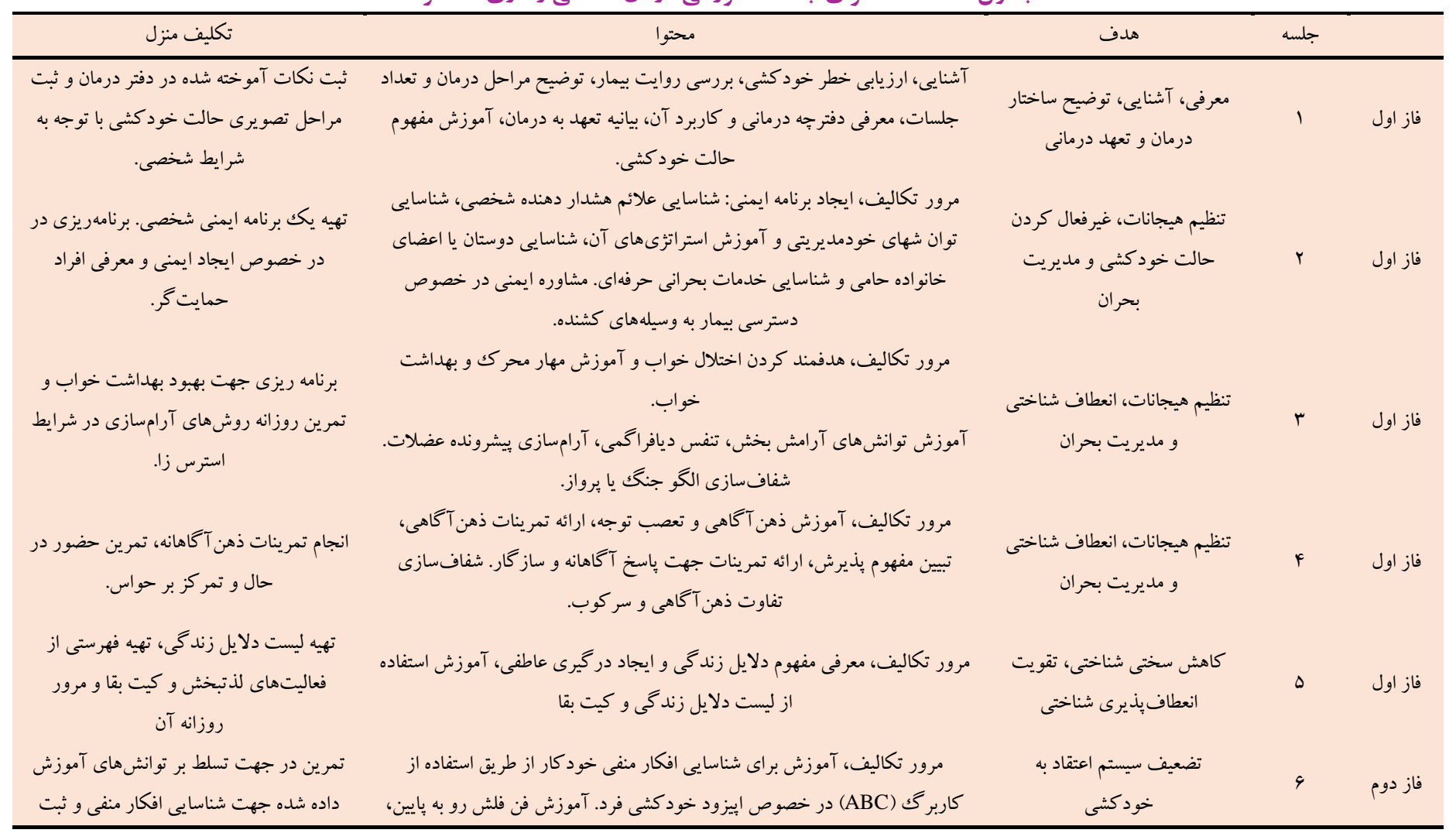




\begin{tabular}{|c|c|c|c|c|}
\hline تكليف منزل & محتوا & هدف & جلسه & \\
\hline \multicolumn{5}{|l|}{ آن. } \\
\hline تمرين تو انش سؤالات جالش برانگيز و ثبت & 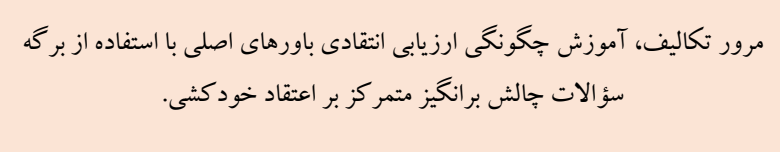 & خود كشى و انعطاف يذيف اعتقاد به & $v$ & فاز دوم \\
\hline انجام تمرين روزانه در خصوص كاربرك & 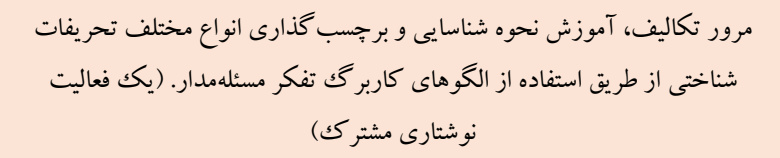 & تضعيف سيستم اعتقاد به & $\wedge$ & فاز دوم \\
\hline 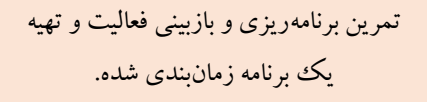 & مرور تكاليف، آموزش و مفهومسازى برنامهريزى فعاليت، زمانبندى. بازبينى فعايت. & تضعيف سيستم اعتقاد به & 9 & فاز دوم \\
\hline تهيه كارت هاى مقابله و مرور آن در طى روز. & مرور تكاليف، آموزش كارتهاى مقابله براى افزايش در گير شدن فرد در فعاليت & تضعيف سيستم اعتقاد به & 1. & فاز دوم \\
\hline تكرار توانشها و مرور دفتر گزارش درمان & خصوص ضعفى كيفيت توانش ها و راهبردهاى آموخته شده در درمان، آموزش مجدود وظيفه تصويرسازى توانشها جهت استحكام مطالب & ييشخيرى از عود & $|r-1|$ & 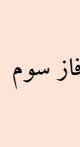 \\
\hline
\end{tabular}

مقياس نمره كذارى به روش ليكرت بوده و دامنه نمرات هرسؤال (Y-•) مى

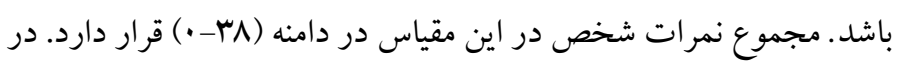

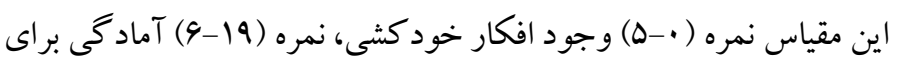

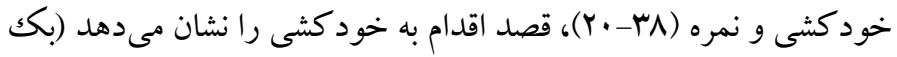

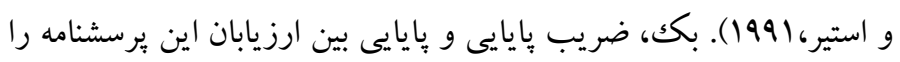

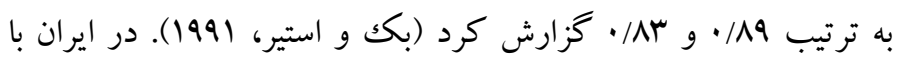

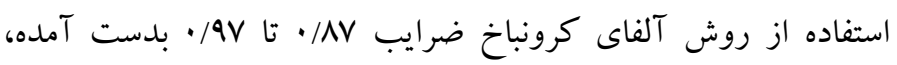

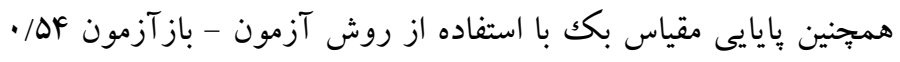
بدست آمده است و نيز قابليت اعتماد مقياس با استفاده از روش آلفاى كرونباخ ه 9 • • مىباشد (انيسى، فتحى آشتيانى، سلطانىنزاد و اميرى،

يرسشنامه تنظيم شناختى هيجان ${ }^{\Upsilon}$

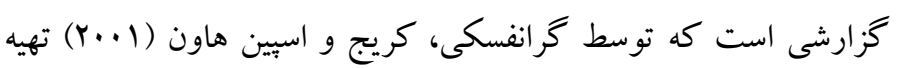
شده است. اين برسشنامه شامل وب گويه مىباشد. فرم 11 سؤالى اين

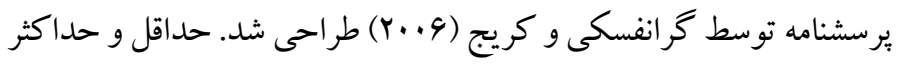
نمره در هر زير مقياس به ترتيب r و •ا مى باشد. هر خرده مقياس از جهار

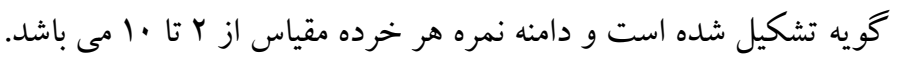
از بين نُه خرده مقياس برسشنامه تنظيم شناختى هيجان، جمع نمرات ينج

${ }^{3}$. Cognitive Emotion Regulation Questionnaire (CERQ)
يرسشنامه افسردگى بكك' (BDI-II): اين يرسشنامه شكل بازنگرى شده

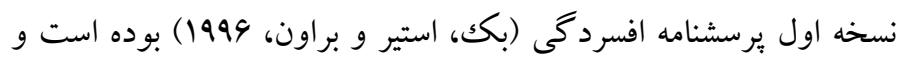

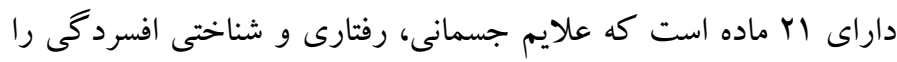

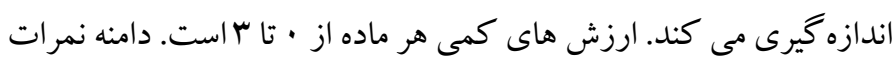

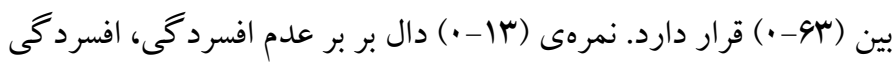

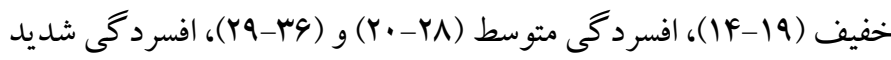

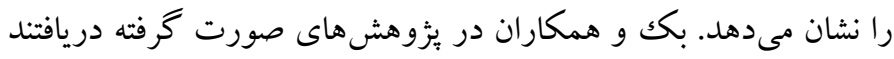

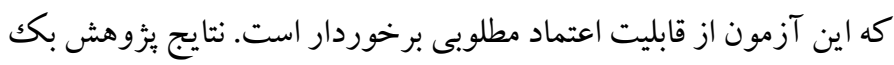

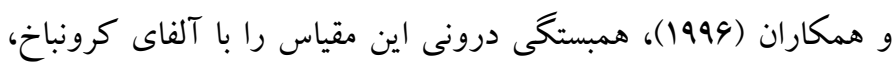

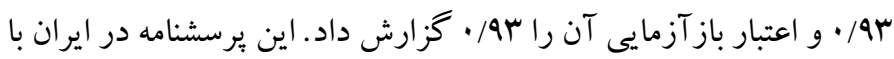

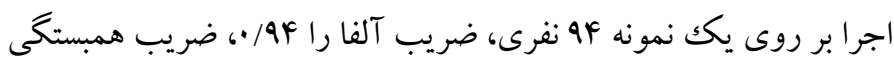

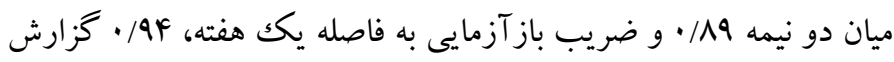

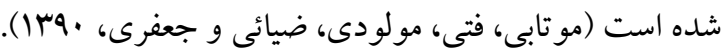

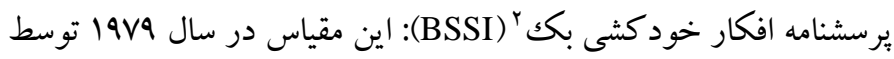

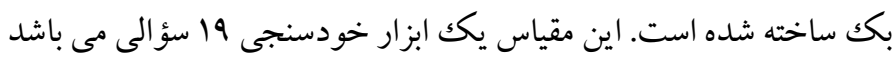

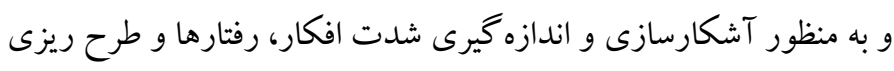
براى ارتكاب به خودكشى در طى هفتهى كذشته تهيه شده است. در اين

${ }^{2}$. Beck Suiside Scale Ideation 
. كروه درمان شناختى - رفتارى مختصر و در گروه گو اه ديِلم بود (به تر تيب

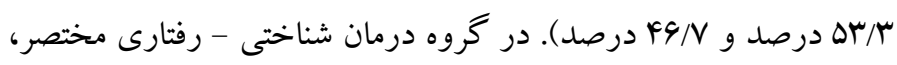

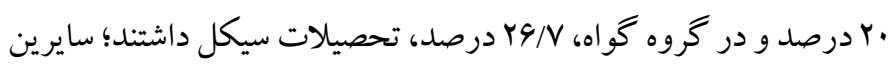

$$
\text { كارشناسى بودند. }
$$

از نظر وضعيت تأهلى، بيشترين مشاركت كننده در هردو كروه، مجرد بودند

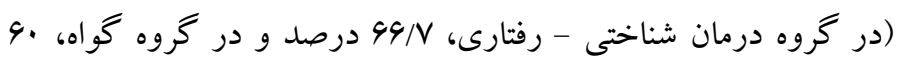
درصد). 49/49 درصد گروه گواه و گروه درمان شناختى - رفتارى مختصر، خانهدار بودند و سايرين شاغل بودند. جدول r يافته هاى توصيفى متغيرهاى يزٔوهش در سه مرحله ارزيابى بيش آزمون، يس آزمون و بيگگيرى را به تفكيكك مراحل نشان داده است.
خرده مقياس، نشخوار ذهنى، يذيرش، سرزنش خود، سرزنش ديخران، فاجعه آميزيندارى، راهبردهاى سازشيافته و جمع نمرات جهار خرده مقياس توجه مثبت مجدد، توجه مجدد به برنامهريزى، ارزيابى مثبت، ديد كاه گيرى راهبردهاى سازش نايافته را تشكيل مى مدهند. پيايايى بازآزمايى نشان داد كه راهبردها از ثبات نسبى برخورداراند و همسانى

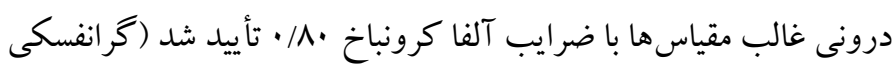

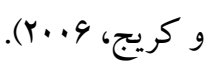
در بثزوهش بششارت و بزازيان (r (r I)، يايايى باز آزمايى و همسانى درونى ير سشنامه M سؤالى در حد رضايتبخش بوده و ضرايب آلفاى كرونباخ مقياس هاى برسشنامه براى FVA شر كت كننده بالاى •^/ • ارزيابى شد. بافْته تحليل دادههاى جمعيت شناختى نشان داد كه ميانخين سن شر كت كنند

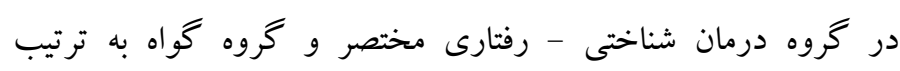

\begin{tabular}{|c|c|c|c|c|c|c|c|c|c|c|c|c|c|c|}
\hline \multirow{3}{*}{ يبيرى } & \multicolumn{2}{|l|}{ بيشينه } & \multicolumn{3}{|c|}{ كمينه } & \multicolumn{3}{|c|}{ انحراف استاندارد } & \multicolumn{3}{|c|}{ ميانگين } & \multirow{3}{*}{\multicolumn{2}{|c|}{ نوبت اندازه گيرى }} & \multirow{3}{*}{$\begin{array}{l}\frac{4}{2} \\
\frac{1}{3} \\
3 \\
3\end{array}$} \\
\hline & پֶس & ييش & $\varepsilon<$ & "ֶ & ييش & $<$ & بֶ & ييش & $<$ & "ֶ & ييش & & & \\
\hline & آزمون & آزمون & "يّيرى & آزمون & آزمون & "ِي & آزمون & آزمون & "ي ي-يرى & آزمون & آزمون & & & \\
\hline 11 & 19 & rᄉ & $\Delta$ & $\Delta$ & 1. & T/FTr & $r / .9 F$ & $V / r \cdot q$ & 1. & 1. & rq & آزمايش & & \\
\hline pq & \&1 & Fr & 11 & $\wedge$ & ri & N/rYI & N/YMG & G/VNI & $r \Delta / 99 \mathrm{~V}$ & $r \Delta / \& g V$ & rV/ITr & كواه & & \\
\hline 11 & ir & rF & $\cdot$ & . & 11 & T/YF. & r/AF. & f/ror & r/amr & $r / r \ldots$ & IV/99V & آزمايش & & \\
\hline rI & IV & 19 & 1 & $r$ & 1. & F/AVG & $F / F V D$ & r/aGr & 11/9rT & $I r / A$ & IF/NTr & كواه & & \\
\hline rq & $F_{1}$ & r & rq & YA & ir & $r / 99 \mathrm{~V}$ & $r / I r V$ & r/Yar & $\mu F / F \ldots$ & $r \Delta / r q V$ & WN/FGV & آزمايش & & $\bar{q}$ \\
\hline mF & rA & rq & ir & iv & ir & $\Delta / \cdot F I$ & $r / \mu \cdot q$ & r/9DF & TI/ITr & $\mathrm{r} 1 / 99 \mathrm{~V}$ & $r \cdot / r q V$ & كواه & & $\frac{\hat{s}}{y}$ \\
\hline rI & Yr & f. & ir & ir & r & r/YVF & Y/lQF & F/VRq & $19 / 4 \ldots$ & $19 / K 9 V$ & $r \cdot / r \cdot$. & آزمايش & & 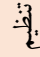 \\
\hline rr & ra & rq & 11 & r. & rI & $r / \cdot r$ & $F / F F V$ & $r / Q \cdot r$ & rq/OHT & $\mathrm{rV} / .9 \mathrm{~V}$ & $r V / F q V$ & كواه & & s: \\
\hline
\end{tabular}

فرض خطى بودن حاكى از خطى بودن رابطه متغيرهاى آزمون تحليل

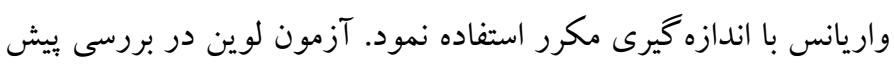

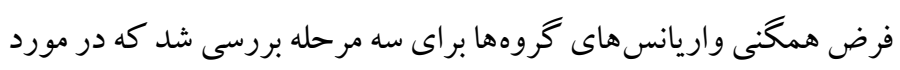

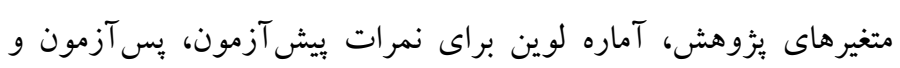

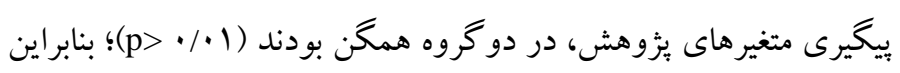
اين بيش فرض نيز تأييد شد.

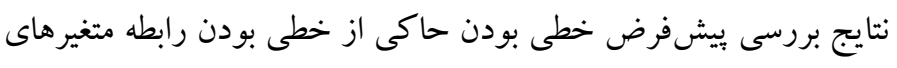

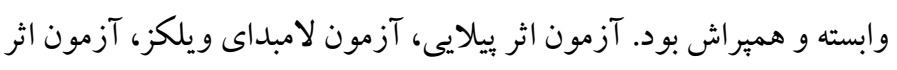

بر اساس جدول rا، بين ميانگين نمرات متغيرهاى بزوهشى دو گروه در سه مرحله ارزيابى تفاوتهايى وجود دارد. بهمنظور بررسى معنادارى اين

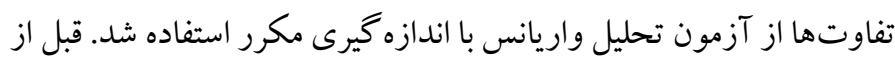

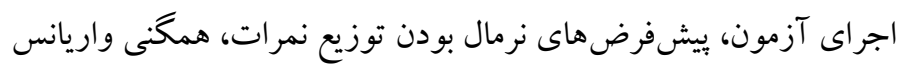
ها، خطى بودن و كرويت بررسى شدند. در بررسى نرمال بودن، نتايج

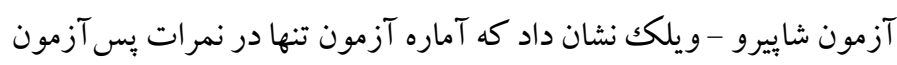

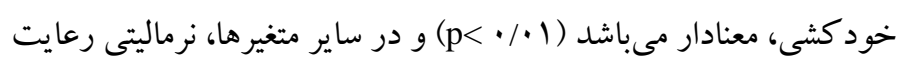
شده است؛ بر اساس قانون خدشهنايذيرى مى توان از نتايج بررسى بيش 


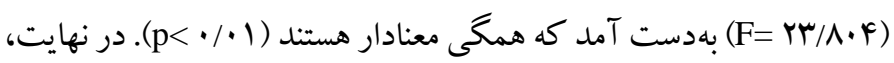
آزمون كرويت ماجلى در بررسى كرويت نشان داد براى دو متغير افكار خود كشى و راهبرد تنظيم هيجانى سازشنايافته ييشفرض كرويت رد مىشود ( ( • > p)؛ كه براى اصلاح درجات آزادى از آزمون كرينهاوس

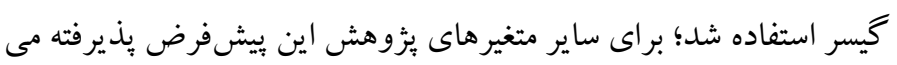

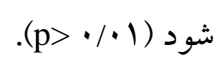

״س از بررسى بيشفرضها، نتايج تحليل واريانس با اندازه گيرى مكرر براى سه مرحله ارزيابى در دو گرووه درمان شناختى - رفتارى مختصر و كو اه

$$
\text { در جدول ب كزارش شده است. }
$$

يس از بررسى بيشفرضها، نتايج تحليل واريانس با اندازه گيرى مكرر براى سه مرحله ارزيابى در دو گروه درمان شناختى - رفتارى مختصر و كو اه

$$
\text { در جدول س گز ارش شده است. }
$$

توان آزمون در مورد متغيرهاى يزٔوهش بالاتر از 91/ • گزارش شده است؛ كه بررسى نتيجه توان آزمون حاكى از قابليت تبيين تفاوتهاى درون آزمودنى و بين آزمودنى است. ميزان تبيين اين تفاوت ها در ستون اندازه اثر

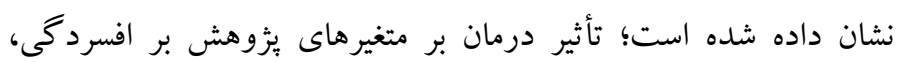
افكارخود كشى، راهبرد تنظيم هيجان سازش يافته و سازشنايافته، به ترتيب

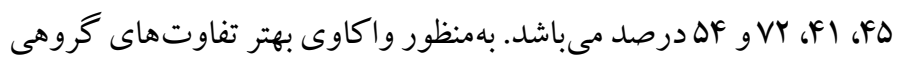
در زمانهاى ارزيابى، از آزمون بونفرونى استفاده شد كه نتايج آن در جدول

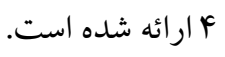

هتلينك و آزمون روى بزركترين ريشه براى اثرات بين آزمودنى كروه و براى اثرات درون آزمودنى زمان (F= rV/NFV)

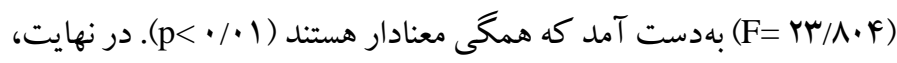

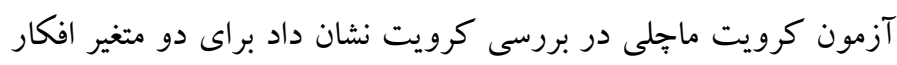

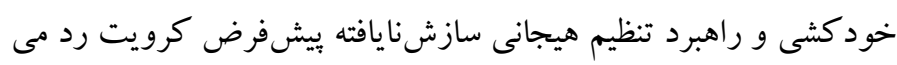

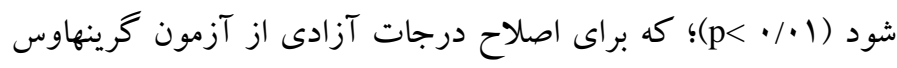

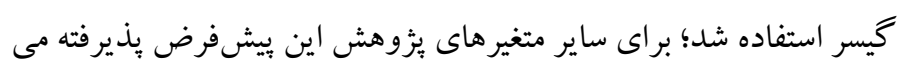

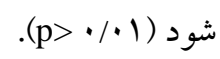
در جدول با، نتايج آزمون تحليل واريانس با اندازه گيرى مكرر، نمايش داده

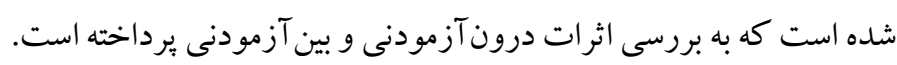

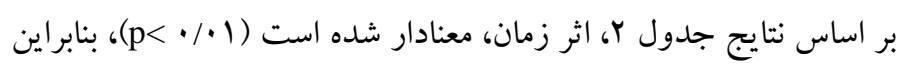

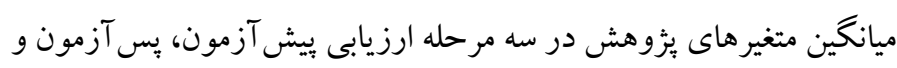

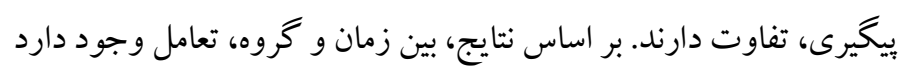

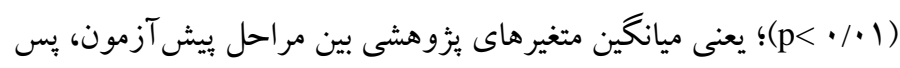

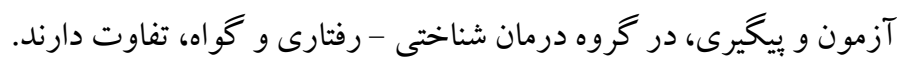

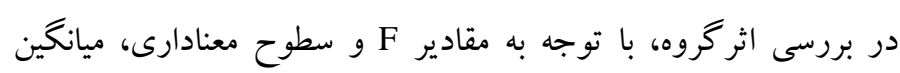

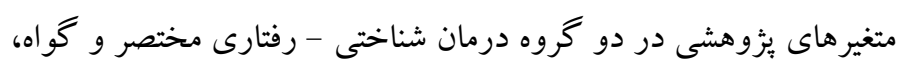

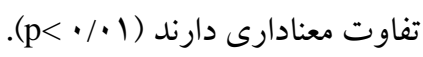

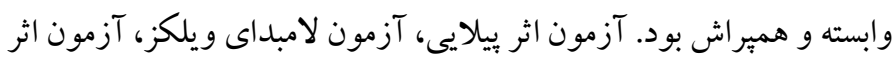

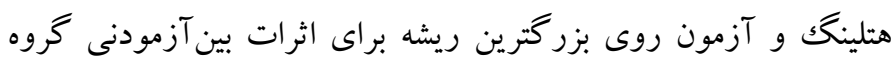

\begin{tabular}{|c|c|c|c|c|c|c|c|c|c|c|}
\hline آزمون & اندازه & معنادارى & Tماره F & مجذيانكين & آزادى درجه & مجذورات مجموع & منبع & اثرات & متغير & عنوان \\
\hline 1 & .191. & $<\cdot / \cdot \cdot 1$ & $\Delta 9 / / 491$ & $1 . \Delta V / \Delta F F$ & $r$ & $r \mid 1 \Delta / \cdot \wedge q$ & زمان & & \multirow{3}{*}{ افسردگیى } & \multirow{3}{*}{ - } \\
\hline 1 & $\cdot / 9 \cdot 4$ & $<\cdot / \cdot \cdot 1$ & $\mathrm{Fr} / 9 \Delta \mathrm{V}$ & $V \Delta Q / A V \wedge$ & r & $1019 / V \Delta 9$ & تعامل & & & \\
\hline.$/ 999$ & $\cdot / 4 \Delta 1$ & $<\cdot / \cdot \cdot 1$ & $r Y / Q \Delta \Lambda$ & YIFI/TKF & 1 & YIFI/MFF & كروه & بين آزمودنى & & \\
\hline 1 & - NOr & $<\cdot / \cdot \cdot 1$ & $\Lambda \Delta / \Delta \cdot q$ & $994 / 9 \pi T$ & $1 / F \Delta r$ & $\mid F F F / I D G$ & زمان & & \multirow{3}{*}{ افكار خود كشى } & \multirow{3}{*}{-} \\
\hline 1 & . & $<\cdot / \cdot \cdot 1$ & $F F / M \Lambda Q$ & $\Delta 19 / T A V$ & $1 / F \Delta r$ & FVQ/GYY & تعامل & & & \\
\hline.$/ 99$ & $\cdot / F \mid f$ & $<\cdot / \cdot \cdot 1$ & $19 / V F V$ & $914 / 911$ & 1 & $914 / 911$ & كروه & بين آزمودنى & & \\
\hline 1 & . /V9D & $<\cdot / \cdot \cdot 1$ & $91 / \cdot \cdot v$ & $v 99 / r \ldots$ & r & lorN/9.. & زمان & & \multirow{3}{*}{ سازش يافتكى } & \multirow{6}{*}{ 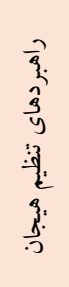 } \\
\hline 1 & $\cdot / N$ & $<\cdot / \cdot \cdot 1$ & $9 N / 9 D F$ & $\Delta \Lambda \cdot / M F F$ & r & 119.1919 & تعامل & & & \\
\hline 1 & $\cdot / N r$. & $<\cdot / \cdot \cdot 1$ & V1/999 & $1 Q V \cdot / A F F$ & 1 & $10 V \cdot / \Lambda F F$ & كروه & بين آزمودنى & & \\
\hline 1 & .1999 & $<\cdot / \cdot \cdot 1$ & $\Delta 9 / \Delta \Delta Q$ & VIF/rOY & $1 / 0.1$ & $1 \cdot V r / \cdot r r$ & زمان & . & \multirow{3}{*}{ سازشنايافتخى } & \\
\hline 1 & .1940 & $<\cdot / \cdot \cdot 1$ & $49 / V .9$ & $\Delta \wedge Q / \Lambda Y \mu$ & $1 / 0.1$ & $M \Delta \Delta / Y G V$ & تعامل & & & \\
\hline 1 & . /QFF & $<\cdot / \cdot \cdot \mid$ & $M / 4 \cdot 9$ & Nkq/F.. & 1 & $\Lambda \notin g / 4 \ldots$ & كروه & بين آزمودنى & & \\
\hline
\end{tabular}
و وبراى اثرات درون آزمودنى زمان (F= TV/NFV)

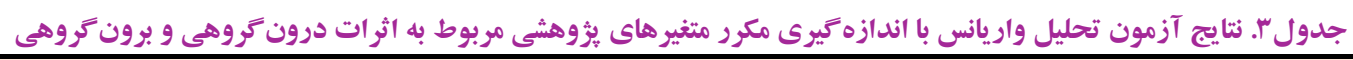


جدول ع. مقايسه زوجى بين تروههاى آزمايش و كواه در هريك از مراحل سنجش

\begin{tabular}{|c|c|c|c|c|c|c|c|c|c|}
\hline \multicolumn{2}{|c|}{ فاصله اطمينان 9ه٪ براى تفاوتها } & \multirow{2}{*}{ سطح معنادارى } & \multirow{2}{*}{ خطاى استاندارد } & \multirow{2}{*}{ تفاوت ميانگين (I-J) } & \multirow{2}{*}{ J كروه J } & \multirow{2}{*}{ I كروه } & \multirow{2}{*}{ مرحله } & \multirow{2}{*}{ متغير } & \multirow{2}{*}{ مقياس } \\
\hline حدبالا & حد يايين & & & & & & & & \\
\hline V/IF. & $-r / f \cdot V$ & $\cdot / F V F$ & $r / \Delta V F$ & $1 / 19 V$ & كواه & آزمايش & ييش آزمون & & \\
\hline$-1 \cdot / \mathrm{Alr}$ & $-r \cdot / T r$. & $<\cdot / \cdot \cdot 1$ & T/YVY & $-10 / 49 V$ & كواه & آزمايش & يֶ آزمون & افسردحىى & - \\
\hline$-1 \cdot / 9 \cdot 1$ & $-Y \cdot / F r \Delta$ & $<\cdot / \cdot \cdot 1$ & T/MYT & $-10 / 99 \mathrm{~V}$ & كواه & آزمايش & ييخيرى & & \\
\hline$\Delta / 9 V \Delta$ & $\cdot / 191$ &.$/ r v$ & $1 / \pi r q$ & r/QTT & كواه & آزمايش & بِيش آزمون & & \\
\hline$-9 / 4 N 1$ & $-\mid Y / V 19$ & $<\cdot / \cdot \cdot 1$ & 1/DYT & $-9 / 9 .$. & كواه & آزمايش & يس آزمون & افكار خود كشى & - \\
\hline$-\Delta / q \cdot F$ & $-1 Y / .99$ & $<\cdot / \cdot \cdot 1$ & $1 / 01 Y$ & $-9 / \cdots$ & كواه & آزمايش & ييخيرى & & \\
\hline$\cdot / A \cdot 1$ & $-k / f \cdot 1$ &.$/ 19 \mathrm{~V}$ & $1 / T V$ & $-1 / A .$. & كواه & آزمايش & يِش آزمون & & \\
\hline $19 / \cdot \cdot 1$ & $11 / 194$ & $<\cdot / \cdot \cdot 1$ & $1 / 1 V 9$ & $1 r / 9 .$. & كواه & آزمايش & 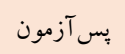 & سازش يافتكى & $\bar{q}$ \\
\hline 19/YAr & $1 . / r \Delta$. & $<\cdot / \cdot \cdot 1$ & $1 / F V Y$ & Ir/YgV & كواه & آزمايش & ييخيرى & & it \\
\hline $9 / 19$. & $-\cdot / N Y F$ &.$/ 11 \mathrm{~V}$ & $1 / 911$ & T/NTT & كواه & آزمايش & بيش آزمون & & t \\
\hline$-\wedge / 1 \Lambda 9$ & $-|r / F| f$ & $<\cdot / \cdot \cdot 1$ & $1 / Y V 9$ & $-1 \cdot / \Lambda \cdot$. & كواه & آزمايش & يس آزمون & سازشنايافتكى & s: \\
\hline -VIMAF & $-I Y / V A Y$ & $<\cdot / \cdot \cdot 1$ & $1 / 190$ & - $1 \cdot / \pi r r$ & كواه & آزمايش & بيخيرى & & $y$ \\
\hline
\end{tabular}

راهنما: در جدول روابط غير معنادار سايه زده شدهاند.

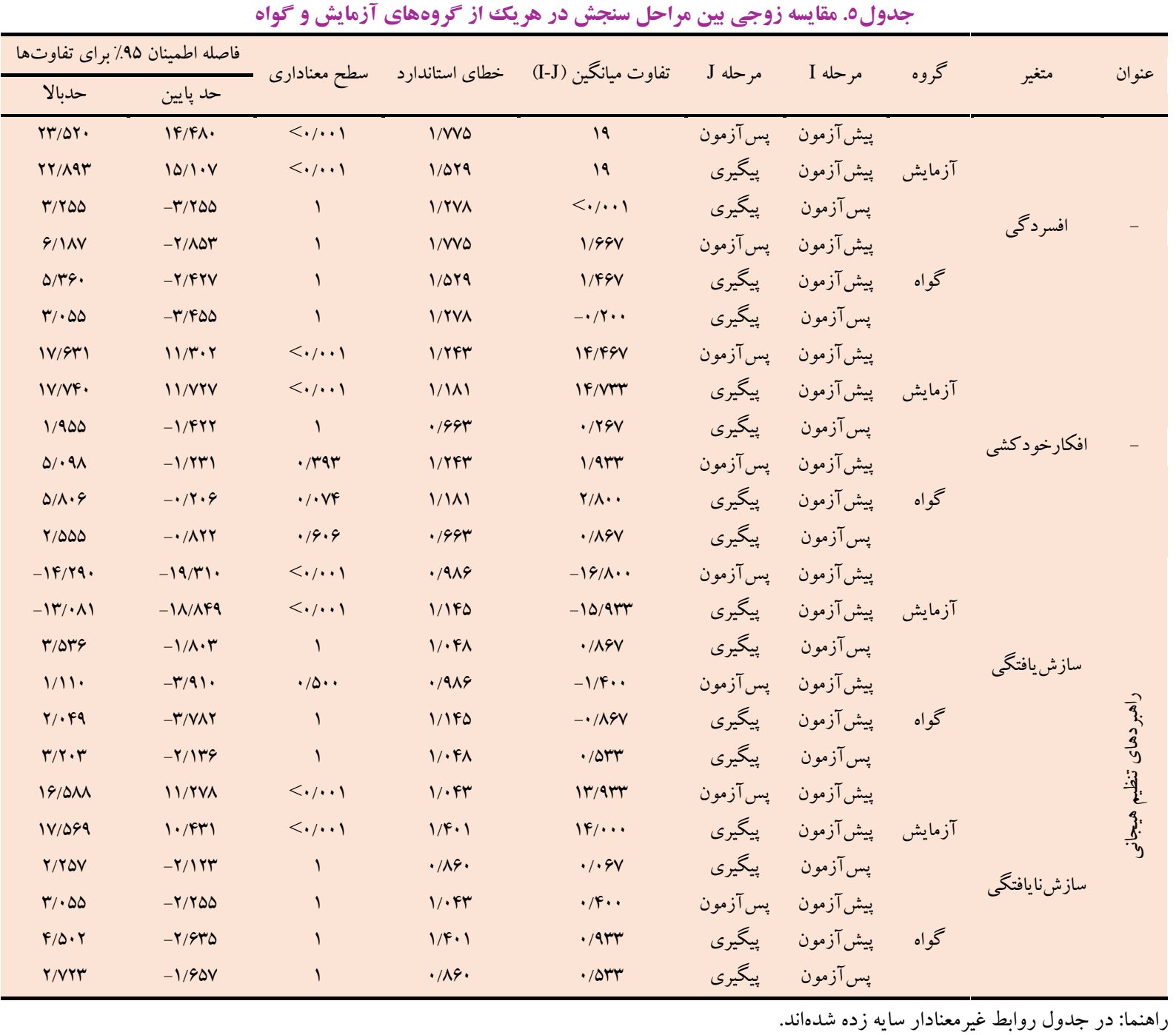


بثروهش حاضر نشان داد كه اين درمان بر كاهش شدت علايم افسردگى إنى

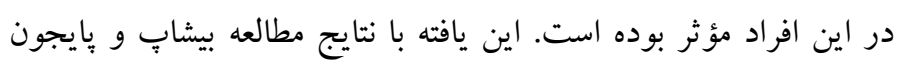

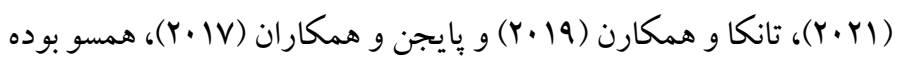

است.

در تبيين اين يافته مى توان كفت كه ساختار درمان شناختى رفتارى مختصر

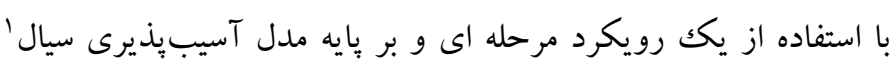

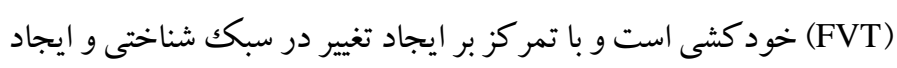
بينش نسبت به سو گيرىهاى شناختى و درك ارتباط افكار، هيجانات و

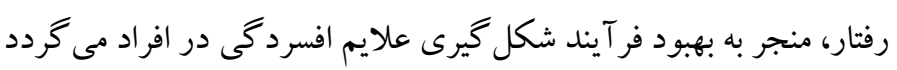

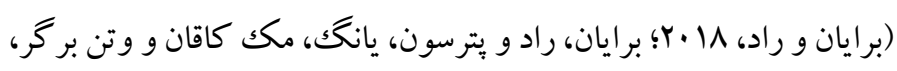
مطابق با اين مدل، باورهاى هستهاى خود كشى از جمله عدم اشتياق، سنخينى

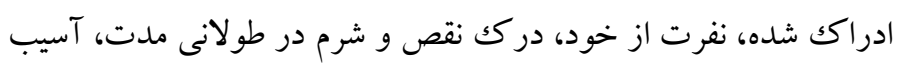

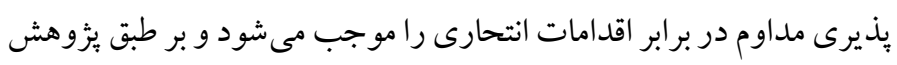

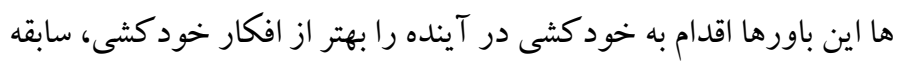

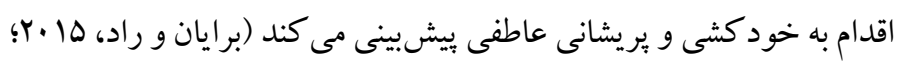

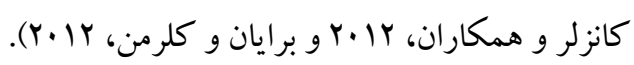

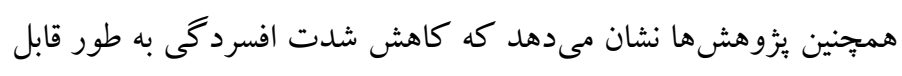

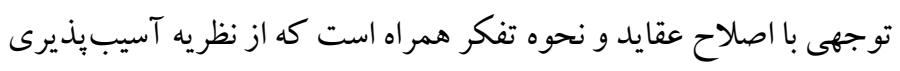

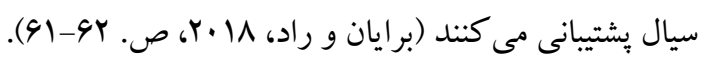
در واقع سو گيرىهاى شناختى با خطر افكار و اقدام به خود كشى در آينده

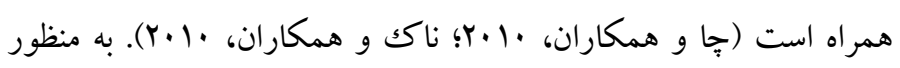
هدف قرار دادن مؤثر اين آسيبذيذيرىهاى شناختى، بيماران ابتدا بايد

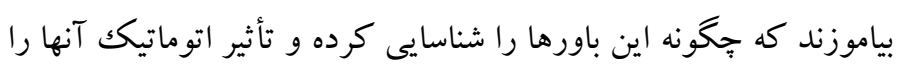
در عواطف و اعمالشان تشخيص دهند. بنابراين تمركز بر ارزيابى مجدد باد

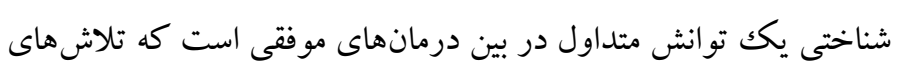

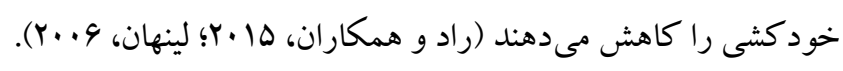

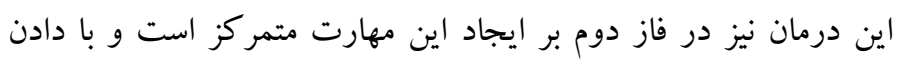

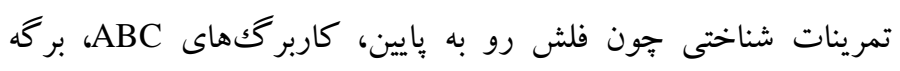

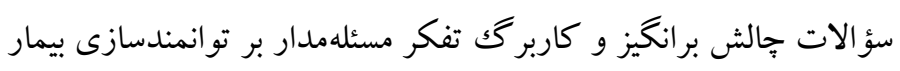
در اين خصوص تأكيد دارد. همجنين در حوزه رفتارى، اين درمان با قرار
بر اساس جدول Fا، بيش آزمون متغيرهاى بثوهش، در دو گروه درمان

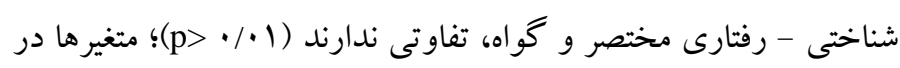

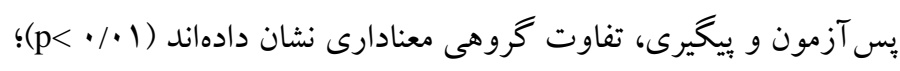

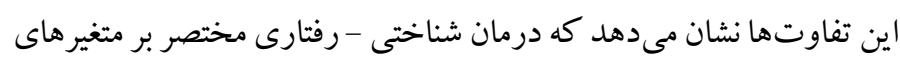

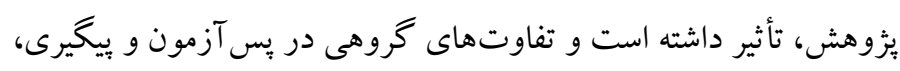

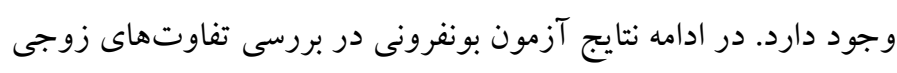

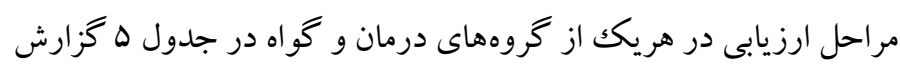
شده است. بر اساس جدول ه، در خروه درمان شناختى - رفتارى مختصر بين مراحل

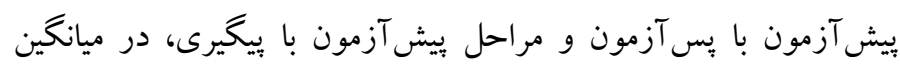

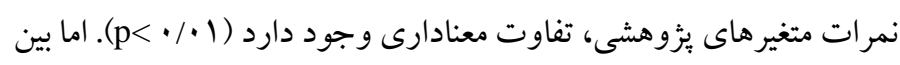

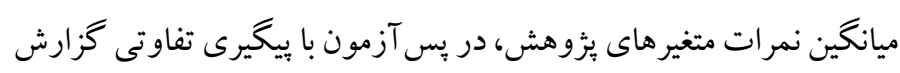

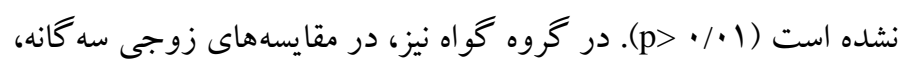

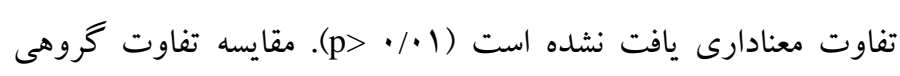
ميانخين هاى متغيرهاى بثزوهشى در هر مرحله ارزيابى (جدول مادى) و مقايسه

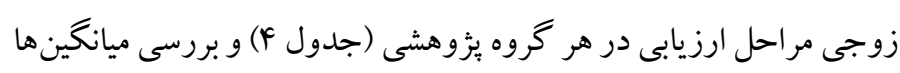

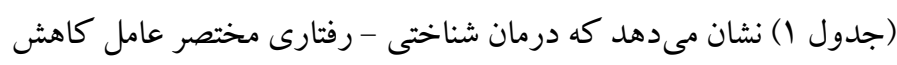

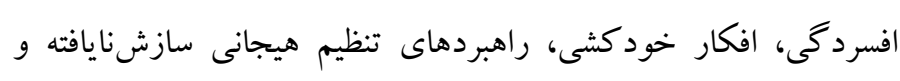
عاملى در جهت افزايش راهبردهاى تنظيم هيجانى سازش يافته است.

بحث و نتيجه تيرى اين بزوهش با هدف بررسى اثربخشى درمان شناختى - رفتارى مختصر بر

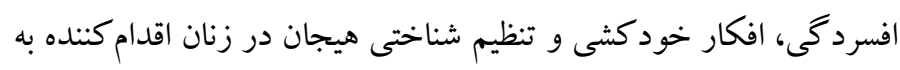
خود كشى در شهر اصفهان صورت گرفت. نتايج نشان داد كه اين درمان

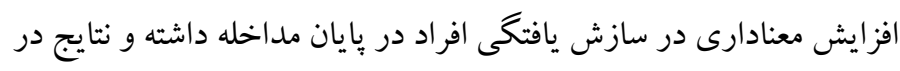
دوره بيخيرى يكك ماهه ثبات داشته است. براى اينكه يكك درمان كاربرد عملى داشته باشد، تأثير راهبردها بر عوامل ئل

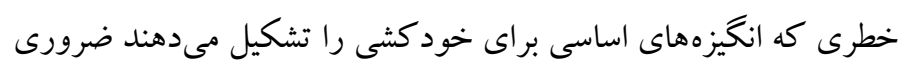

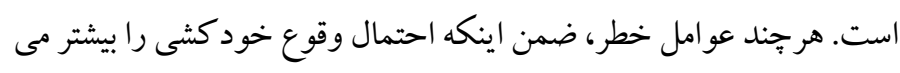

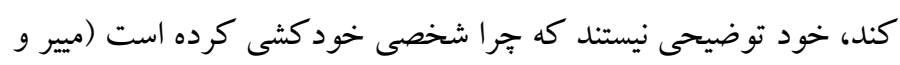

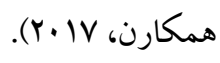

1. Fluid vulnerability theory (FVT) 
برايان و راد، 1) (Y). كيت بقا از طريق دو استراتزى خاص مهارتهاى

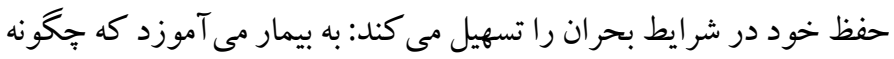

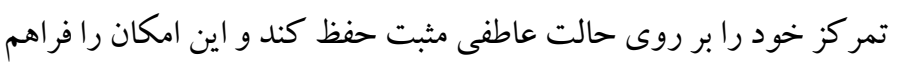

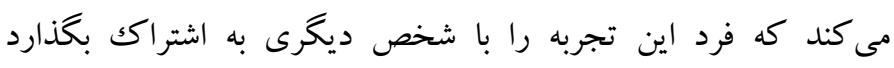

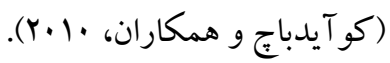

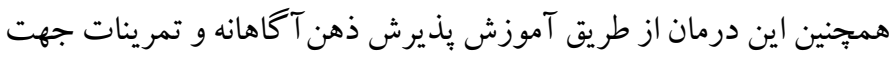

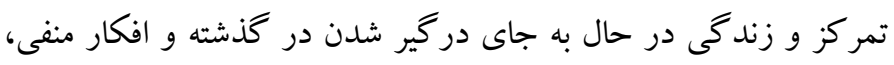

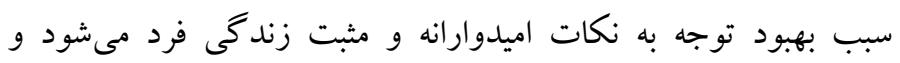
فر آيندهاى شناختى جديد تسهيل شده و فرد حالات عاطفى مثبت را كه ونه منجر به دورى از افكار منفى مىشود تجربه خواهد كرد (برايان و راد،

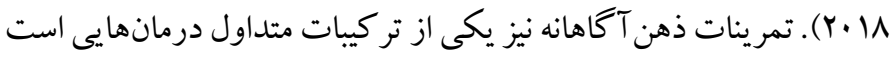
كه بطور مؤثر افكار خودكشى و اقدام به خودكشى را كاهش مى مدهد

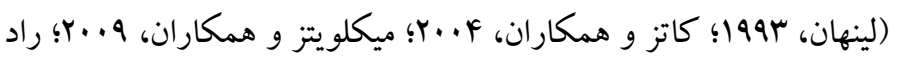

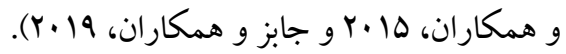
از سويى ديخر، يافته هاى اين مطالعه نشان داد كه درمان شناختى و رفتارى ولى هاني مختصر بر افزايش راهبردهاى سازشيافته و كاهش راهبردهاى سازش يُش

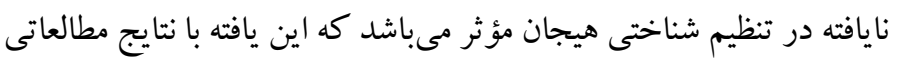

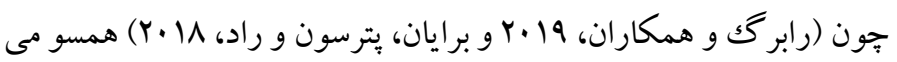
باشد.

در حوزه رفتارى حالت خودكشى، عوامل خطرساز اصلى شامل نقص

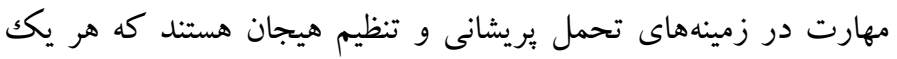
احتمال مقابله ناساز گار در ياسخ به موقعيتهاى استرسزا و و تحريكك كننده حوادث را افزايش مىدهد و اين درمان در فاز اول، مستقيماً نقايص اين نهاب

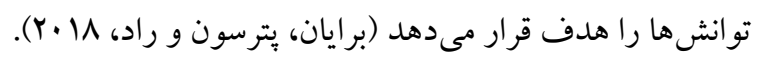
يكك مؤلفه اصلى اين درمان برنامه ايمنى است كه هدف اصلى آنى آن كمكك

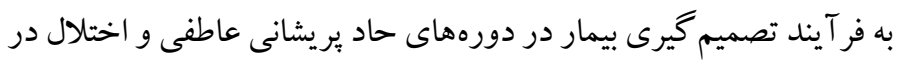
حل مسئله است. اين برنامه منحصر به فرد است زيرا يكك رويكرد منظم و جامع براى حفظ ايمنى در بيماران خود كشى است و بهترين روش مداخله كو تاه مدت است كه شامل استراتزىهاى كاهش خطر خود كشى و ايجاد مهارتهاى حل مسئله و كنترل هيجان، افزايش حمايت اجتماعى و

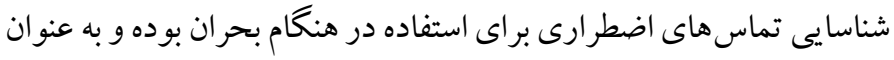

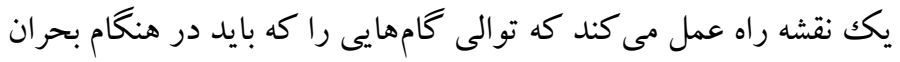

دادن تمرينات رفتارى فعالسازى و بازبينى فعاليت و برنامهريزى، سعى در

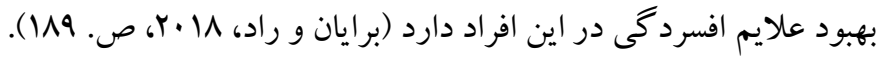

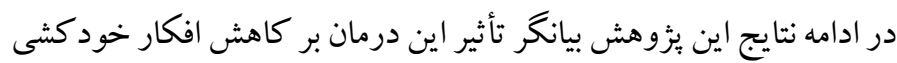

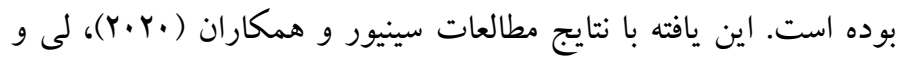

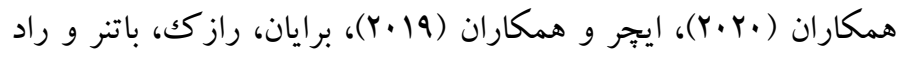
(Y.19) و نيز مطالعه برايان و راز كك (Y) (Y) همسو مىباشد.

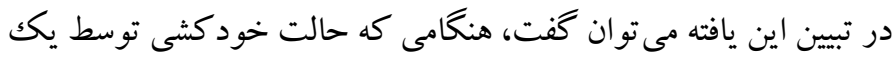

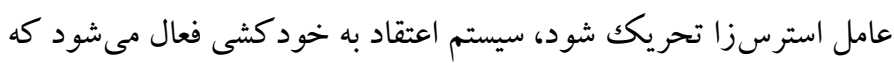

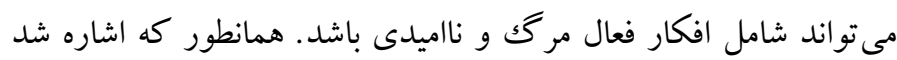

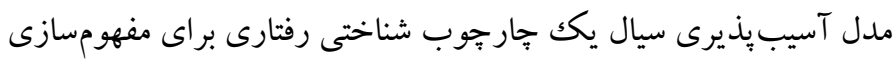
حالتهاى خودكشى است كه براساس نظريه حالت كلى تر روانشناسى

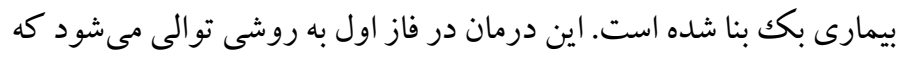
درك عميقى از بيدايش حالت خود كشى را ترويج مى كند و بر غيرفعال

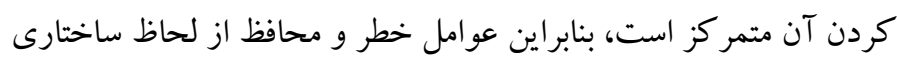

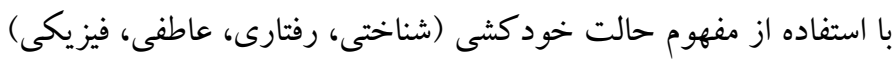
براى بيمار شفافسازى مىشود كه در ايجاد انعطاف شناختى و احساس

خود كار آمدى بيمار نقش مهمى دارد (برايان و راد، 1) · ب، ص. • (1). دراين مدل باور بر اين است كه سيستم اعتقاد به خود كشى نشانكر بروز

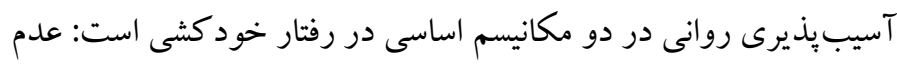
انعطافيذيرى شناختى و نقص در تنظيم هيجانات. بنابراين هر دو اين

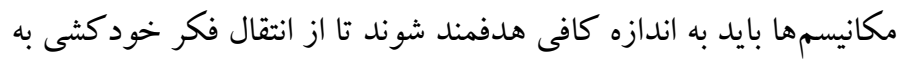
عمل جلو گيرى شودو تمركز فقط روى يكك (يا جند مؤلفه) سيستم اعتقاد

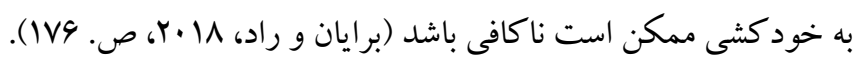
در واقع نقص در انعطافيذيرى شناختى، عملكرد اجرايى و تو انايى توليد سريع راهحلهاى بالقوه براى مشكلات را مختل مى كند. بنابراين در فاز اول

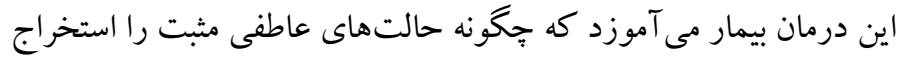

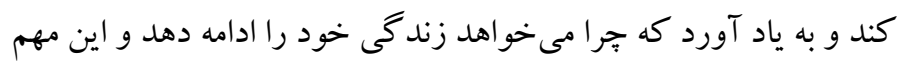
از طريق تكنيككهايى جون ليست دلايل زندگى، كيت بقاو تمرينات ذهن

$$
\text { آكاهى فراهم مى شود. }
$$

هدف اصلى استفاده از ليست دلايل زندگى ودى وديت بقا افزايش انعطاف

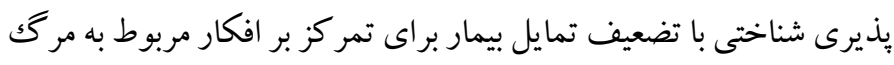

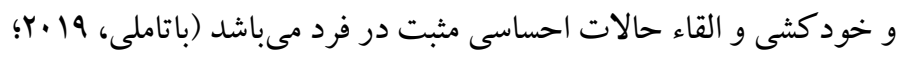


اساس تجارب قبلى، واكنش نشان بدهند، سعى مى كنند كه هر بار به

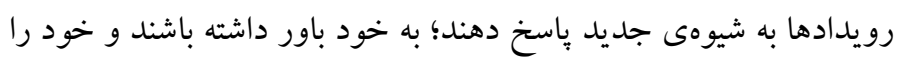

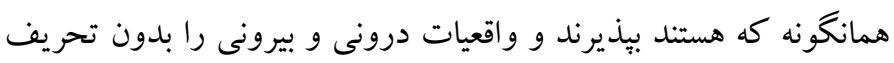

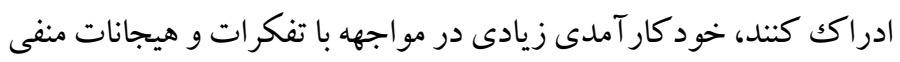

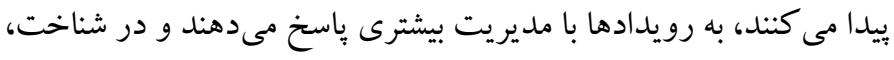

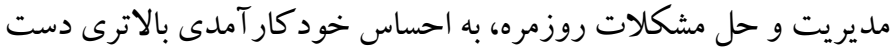
وبيدا مى كنند. از محدوديت هاى اين ئزوهش مى توان به عدم كنترل عوامل زمينهاى و

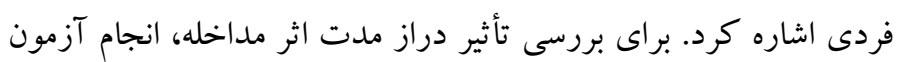

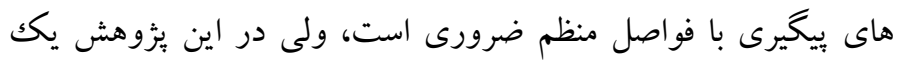

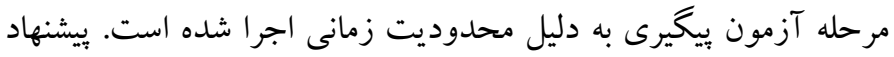

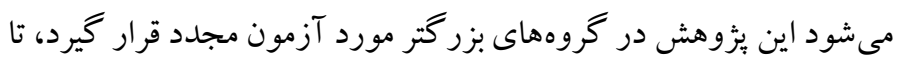

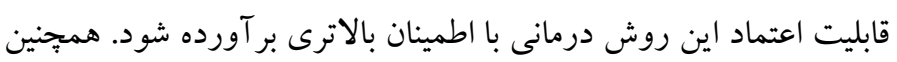
ييشنهاد مى شود واحدهاى روانشناسى و مشاوره در سازمانهاى بهداشتى و

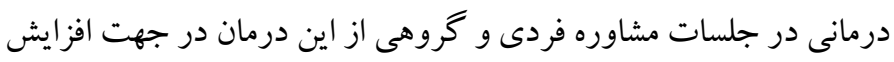
سازش يافتكى افراد اقدام كننده به خود كشى استفاده نمايند.

ملاحضات اخلاقى بيروى از اصول اخلاق بثوهش: ائن مقاله بر گرفته از رساله دكترى نويسنده اول در

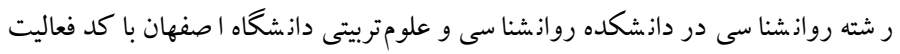

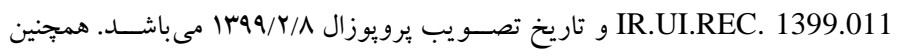

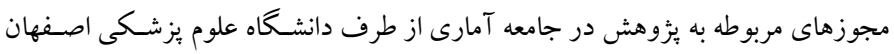
صادر شده است.

حامى مالى: اين يُوهش در قالب رساله دكترى و بدون حمايت مالى مىباشد.

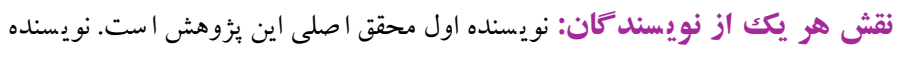
دوم استاد راهنما و نو يسند كان سوم و جهارم استادان مشاور رساله مى نواشند.

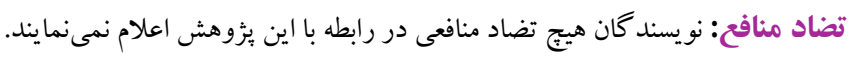

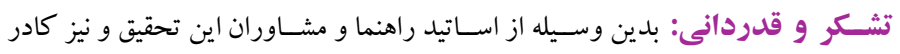
بيمارستانهاى خورشـيد و الزهرا كه در انجام اين تحقيق يارى نمودند تشكر و قدردانى مى گردد.
برداشته شود تشريح مى كند و در نتيجه فروياشى حل مسئله و عدم مهار

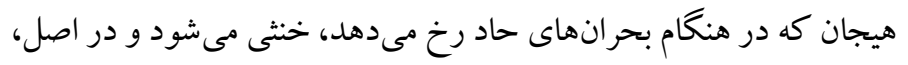

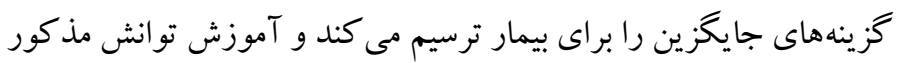

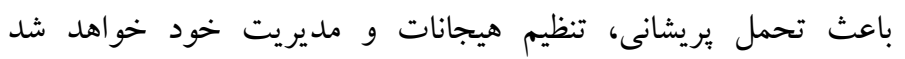

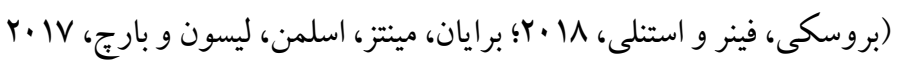

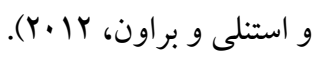

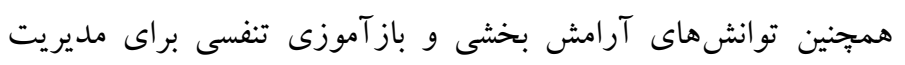

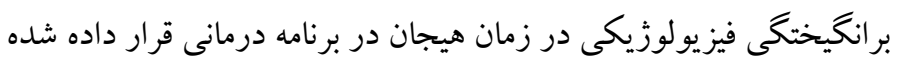

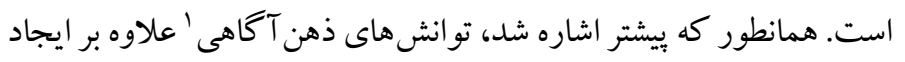

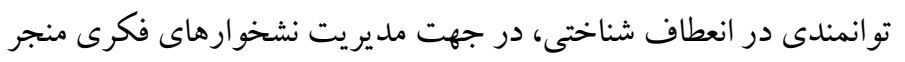

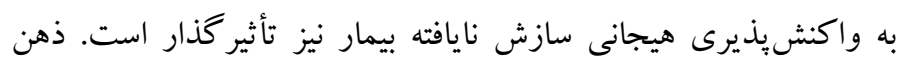

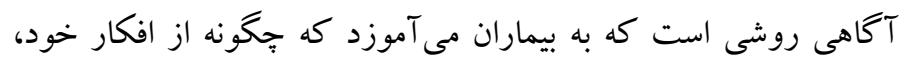
تجربيات روانشناختى داخلى و رفتارهاى خود، آكاهى بيشترى بيدا كنند و

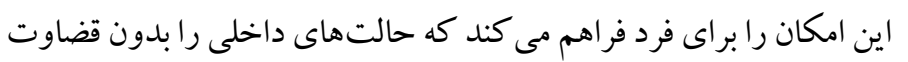
تجربه كنند و از اين طريق ياسخى آكاهانه و ساز كار رافر فراهم كنند (كرن،

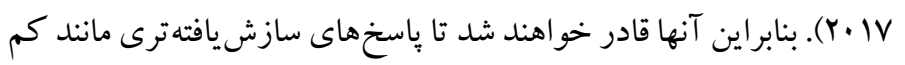
اهميت شمارى؛ تمركز مجدد مثبت؛ ارزيابى مجدد مثبت؛ يذيرش و و

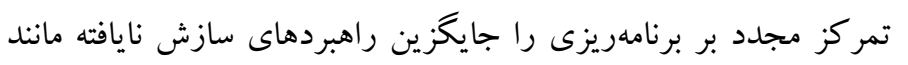
خودسرزنش گرى، فاجعه يندارى و نشخوار فكرى نمايند و در نتيجه فعال

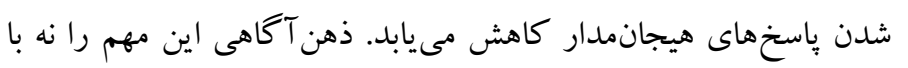

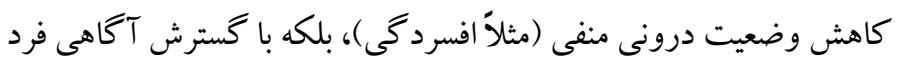

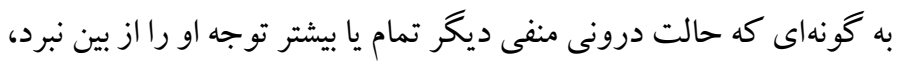

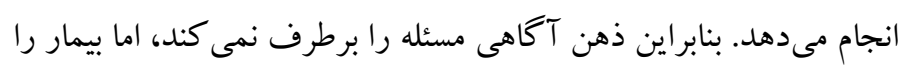

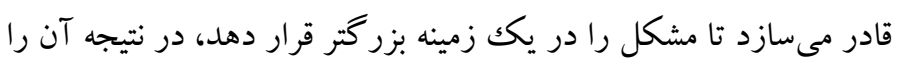

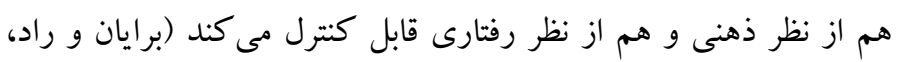
(19V-191. در واقع تمرينات ذهن آكاهى با افزايش انعطاف شناختى فرد بر روى سبك

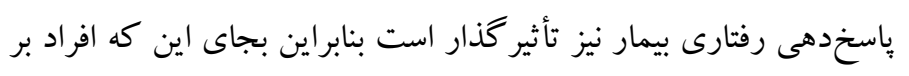




\section{References}

Abdollahi, A., \& Carlbring, P. (2017). Coping style as a moderator of perfectionism and suicidal ideation among undergraduate students. Journal of RationalEmotive \& Cognitive-Behavior Therapy, 35(3): 223-239. [Link]

Abdollahi, A., Talib, M. A., Yaacob, S. N., \& Ismail, Z. (2016). Problem-solving skills and suicidal ideation among Malaysian college students: The mediating role of hopelessness. Academic Psychiatry, 40(2): 261-267. [Link]

Anisi, J., Fathi-Ashtiani, A., Soltaninezhad, A., \& Amiri, M. (2006). Prevalence of suicide ideation and related factors among troops. Mil Med Journal, 8 (2): 113-118. [Link]

Azadi, S., Khosravani, V., King, S., Mohammadzadeh, A., \& Baseri, A. (2020). Effects of Neuropsychological Systems on Psychopathology through Cognitive Emotion Regulation Strategies in Individuals with Suicide Attempts. Cognitive Therapy and Research, 44(1), 229-239. [Link]

Bakhtar, M., \& Rezaeian, M. (2017). The prevalence of suicide thoughts and attempted suicide plus their risk factors among Iranian students: a systematic review study. Journal of Rafsanjan University of Medical Sciences, 15(11), 1061-1076. [Link]

Beck, A. T., Steer, R. A., \& Brown, G. K. (1996). Manual for the Beck Depression Inventory, $2 n$ ed. San Antonio, TX: The Psychological Corporation. [Link]

Beck, A. T., \& Steer, R. A. (1991). Manual for the Beck scale for suicide ideation. San Antonio, TX: Psychological Corporation, 63. [Link]

Bishop, T. M., \& Pigeon, W. R. (2021). Case Study: Brief CBT-I and Medication Taper with a Veteran Experiencing Insomnia and Suicidal Ideation. In Sleep Disorders in Selected Psychiatric Settings (pp. 9-17). Springer, Cham. [Link]

Brodsky, B. S., Spruch-Feiner, A., \& Stanley, B. (2018). The zero suicide model: applying evidence-based suicide prevention practices to clinical care. Frontiers in psychiatry, 9, 33. [Link]

Brown, G. K., Ten Have, T., Henriques, G. R., Xie, S. X., Hollander, J. E., \& Beck, A. T. (2005). Cognitive therapy for the prevention of suicide attempts: A randomized controlled trial. Journal of the American Medical Association, 294(5), 563-570. [Link]

Bryan, C. J., Clemans, T. A., \& Hernandez, A. M. (2012). Perceived burdensomeness, fearlessness of death, and suicidality among deployed military personnel.
Personality and Individual Differences, 52(3), 374379. [Link]

Bryan, C. J., \& Rudd, M. D. (2018). Brief cognitivebehavioral therapy for suicide prevention. Guilford Publications. [Link]

Bryan, C. J., \& Rudd, M. D. (2018). Nonlinear change processes during psychotherapy characterize patients who have made multiple suicide attempts. Suicide and Life-Threatening Behavior, 48(4), 386400 .[Link]

Bryan, C. J., Rudd, M. D., Peterson, A. L., YoungMcCaughan, S., \& Wertenberger, E. G. (2016). The ebb and flow of the wish to live and the wish to die among suicidal military personnel. Journal of Affective Disorders, 202, 58-66. [Link]

Bryan, C. J., Rudd, M. D., Wertenberger, E., YoungMcCaughon, S., \& Peterson, A. (2015). Nonsuicidal self-injury as a prospective predictor of suicide attempts in a clinical sample of military personnel. Comprehensive psychiatry, 59, 1-7. [Link]

Bryan, C. J., \& Rozek, D. C. (2018). Suicide prevention in the military: A mechanistic perspective. Current opinion in psychology, 22, 27-32. [Link]

Bryan, C. J., Rozek, D. C., Butner, J., \& Rudd, M. D. (2019). Patterns of change in suicide ideation signal the recurrence of suicide attempts among high-risk psychiatric outpatients. Behaviour research and therapy, 120, 103392. [Link]

Bryan, C. J., Peterson, A. L., \& Rudd, M. D. (2018). Differential effects of brief CBT versus treatment as usual on posttreatment suicide attempts among groups of suicidal patients. Psychiatric services, 69(6), 703-709. [Link]

Bryan, C. J., Mintz, J., Clemans, T. A., Leeson, B., Burch, T. S., Williams, S. R... Rudd, M. D. (2017). Effect of crisis response planning vs. contracts for safety on suicide risk in U.S. Army soldiers: A randomized clinical trial. Journal of Affective Disorders, 212, 64-72. [Link]

Bottomley, J. S. (2019). Bryan, CJ, \& Rudd, MD (2018). Brief Cognitive Behavioral Therapy (BCBT) for Suicide Prevention. [Link]

Cha, C. B., Najmi, S., Park, J. M., Finn, C. T., \& Nock, M. K. (2010). Attentional bias toward suicide-related stimuli predicts suicidal behavior. Journal of abnormal psychology, 119(3), 616. [Link]

Crane, R. (2017). Mindfulness-based cognitive therapy: Distinctive features. Routledge. [Link]

Diefenbach, G. J., Rudd, M. D., Merling, L. F., Davies, C., Katz, B. W., \& Tolin, D. F. (2020). Brief cognitivebehavioral therapy for suicidal inpatients. Cognitive and Behavioral Practice. [Link] 
Ecker, A. H., Johnson, A. L., Sansgiry, S., Fletcher, T. L., Hundt, N., Petersen, N. J. ... \& Kunik, M. E. (2019). Brief cognitive behavioral therapy reduces suicidal ideation in veterans with chronic illnesses. General hospital psychiatry, 58, 27-32. [Link]

Ehring, T., \& Watkins, E. R. (2008). Repetitive negative thinking as a transdiagnostic process. International journal of cognitive therapy, 1(3): 192-205. [Link]

Garnefski, N., \& Kraaij, V. (2006). Cognitive Emotion Regulation Questionnaire Development of a short 18-item version (CERQ-short). Personality and Individual Differences, 41, 1045-1053. [Link]

Garnefski, N., Kraaij, V., \& Spinhoven, P. (2001). Negative life events, cognitive emotion regulation and emotional problems. Personality and Individual Differences, 30, 1311-1327. [Link]

Hatkevich, C., Penner, F., \& Sharp, C. (2019). Difficulties in emotion regulation and suicide ideation and attempt in adolescent inpatients. Psychiatry research, 271, 230-238. [Link]

Hofstra, E., Van Nieuwenhuizen, C., Bakker, M., Özgül, D., Elfeddali, I., de Jong, S. J., \& van der FeltzCornelis, C. M. (2019). Effectiveness of suicide prevention interventions: a systematic review and meta-analysis. General hospital psychiatry. [Link]

Heffer, T., \& Willoughby, T. (2018). The role of emotion dysregulation: A longitudinal investigation of the interpersonal theory of suicide. Psychiatry research, 260, 379-383. [Link]

Jobes, D. A., Vergara, G. A., Lanzillo, E. C., \& RidgeAnderson, A. (2019). The potential use of CAMS for suicidal youth: building on epidemiology and clinical interventions. Children's Health Care, 48(4): 444-468. [Link]

Kanzler, K. E., Bryan, C. J., McGeary, D. D., \& Morrow, C. E. (2012). Suicidal ideation and perceived burdensomeness in patients with chronic pain. Pain Practice, 12(8), 602-609. [Link]

Katz, L. Y., Cox, B. J., Gunasekara, S., \& Miller, A. L. (2004). Feasibility of dialectical behavior therapy for suicidal adolescent inpatients. Journal of the American Academy of Child \& Adolescent Psychiatry, 43(3), 276-282. [Link]

Klonsky, E. D., May, A. M., \& Saffer, B. Y. (2016). Suicide, suicide attempts, and suicidal ideation. Annual review of clinical psychology, 12, 307-330. [Link]

Korkmaz, S., Keleş, D. D., Kazgan, A., Baykara, S., Gürok, M. G., Demir, C. F., \& Atmaca, M. (2020). Emotional intelligence and problem solving skills in individuals who attempted suicide. Journal of Clinical Neuroscience. [Link]
Lasa-Aristu, A., Delgado-Egido, B., Holgado-Tello, F. P., Amor, P. J., \& Domínguez-Sánchez, F. J. (2019). Profiles of cognitive emotion regulation and their association with emotional traits. Clinical and Health, 30(1), 33-39. [Link]

Lee, D. J., Bryan, C. J., \& Rudd, M. D. (2020). Longitudinal suicide ideation trajectories in a clinical trial of brief CBT for US military personnel recently discharged from psychiatric hospitalization. Psychiatry research, 293, 113335. [Link]

Lew, B., Huen, J., Yu, P., Yuan, L., Wang, D. F., Ping, F. ... \& Jia, C. X. (2019). Associations between depression, anxiety, stress, hopelessness, subjective well-being, coping styles and suicide in Chinese university students. PloS One, 14(7), e0217372. [Link]

Linehan, M. M. (1993). Skills training manual for treating borderline personality disorder: Guilford Press. [Link]

Linehan, M. M., Comtois, K. A., Murray, A. M., Brown, M. Z., Gallop, R. J., Heard, H. L. ... \& Lindenboim, N. (2006). Two-year randomized controlled trial and follow-up of dialectical behavior therapy vs therapy by experts for suicidal behaviors and borderline personality disorder. Archives of general psychiatry, 63(7), 757-766. [Link]

Lynch, T. R., Chapman, A. L., Rosenthal, M. Z., Kuo, J. R., \& Linehan, M. M. (2006). Mechanisms of change in dialectical behavior therapy: Theoretical and empirical observations. Journal of clinical psychology, 62(4), 459-480. [Link]

McManus, S., Bebbington, P. E., Jenkins, R., \& Brugha, T. (2016). Mental Health and Wellbeing in England: the Adult Psychiatric Morbidity Survey 2014. NHS digital. [Link]

Meyer, C. L., Irani, T., Hermes, K. A., \& Yung, B. (2017). Explaining suicide: Patterns, motivations, and what notes reveal: Academic Press. [Link]

Miklowitz, D. J., Alatiq, Y., Goodwin, G. M., Geddes, J. R., Fennell, M. J. V., Dimidjian, S., et al. (2009). A pilot study of mindfulness-based cognitive therapy for bipolar disorder. International Journal of Cognitive Therapy, 2, 373-382. [Link]

Morrison, K. S., \& Hopkins, R. (2019). Cultural identity, Africultural coping strategies, and depression as predictors of suicidal ideations and attempts among African American female college students. Journal of Black psychology, 45(1), 3-25. [Link]

Motabi, F, Fata, L, Moloodi, R, Ziai, K, Jafari, H. (2011). Development and Validation of Depression-Related Beliefs Scale. Iranian Journal of Psychiatry and Clinical Psychology, 17(3): 208-217. [Link] 
National Institute of Mental Health. (April, 2019). Suicide Statistics. Accessed at https://www.nimh.nih.gov/health/statistics/suicide. shtml on 8/30/19. [Link]

Nock, M. K., Park, J. M., Finn, C. T., Deliberto, T. L., Dour, H. J., \& Banaji, M. R. (2010). Measuring the suicidal mind: Implicit cognition predicts suicidal behavior. Psychological Science, 21, 511-517. [Link]

O'Brien, R. W., \& Tomoyasu, N. (2021). Women and suicide: Moving forward on a troubling problem. Medical care, 59, S4-S5. [Link]

Ong, E. (2018). The cognitive and neural basis of suicide: investigating factors that help to identify individuals at risk. University of Salford ,913-918. [Link]

Quoidbach, J., Berry, E. V., Hansenne, M., \& Mikolajczak, M. (2010). Positive emotion regulation and well-being: Comparing the impact of eight savoring and dampening strategies. Personality and individual differences, 49(5), 368373. [Link]

Raj, S., Sachdeva, S. A., Jha, R., Sharad, S., Singh, T., Arya, Y. K., \& Verma, S. K. (2019). Effectiveness of mindfulness based cognitive behavior therapy on life satisfaction, and life orientation of adolescents with depression and suicidal ideation. Asian journal of psychiatry, 39, 58-62. [Link]

Roberge, E. M., Bryan, C. J., Peterson, A., \& Rudd, M. D. (2019). Variables associated with reductions in insomnia severity among acutely suicidal patients receiving brief cognitive behavioral therapy for suicide prevention. Journal of affective disorders, 252, 230-236. [Link]

Rojas, S. M., Gold, S. D., Bryan, C. J., Pruitt, L. D., Felker, B. L., \& Reger, M. A. (2021). Brief CognitiveBehavioral Therapy for Suicide Prevention (BCBTSP) via Video Telehealth: A Case Example during the COVID-19 Outbreak. Cognitive and Behavioral Practice. [Link]

Rudd, M. D., Bryan, C. J., Wertenberger, E. G., Peterson, A. L., Young-McCaughan, S., Mintz, J. ... \& Bruce, T. O. (2015). Brief cognitive-behavioral therapy effects on post-treatment suicide attempts in a military sample: results of a randomized clinical trial with 2-year follow-up. American journal of psychiatry, 172(5), 441-449. [Link]

Rudd, M. D., Joiner, T. E., \& Rajab, M. H. (2001). Treating suicidal behavior: An effective, timelimited approach. Guilford Press. [Link]

Sadri Damirchi, E., Zakibakhsh Mohammadi, N., Amir, B., \& Mohammad, S. (2019). The role of thwarted belongingness, perceived burdensomeness, selfefficacy and ego strength in predicting suicidal ideation of nurses. Health in Emergencies and Disasters, 4(2): 85-92. [Link]

Sanderson, M., Bulloch, A. G., Wang, J., Williams, K. G., Williamson, T., \& Patten, S. B. (2020). Predicting death by suicide following an emergency department visit for parasuicide with administrative health care system data and machine learning. EClinicalMedicine, 100281 .[Link]

Shamsaei, F., Yaghmaei, S., \& Haghighi, M. (2020). Exploring the lived experiences of the suicide attempt survivors: a phenomenological approach. International journal of qualitative studies on health and well-being, 15(1), 1745478. [Link]

Siegmann, P., Willutzki, U., Fritsch, N., Nyhuis, P., Wolter, M., \& Teismann, T. (2019). Positive mental health as a moderator of the association between risk factors and suicide ideation/behavior in psychiatric inpatients. Psychiatry research, 273, 678-684. [Link]

Sinyor, M., Williams, M., Mitchell, R., Zaheer, R., Bryan, C. J., Schaffer, A. ... \& Tien, H. (2020). Cognitive behavioral therapy for suicide prevention in youth admitted to hospital following an episode of selfharm: a pilot randomized controlled trial. Journal of affective disorders, 266, 686-694. [Link]

Stanley, B., \& Brown, G. K. (2012). Safety planning intervention: a brief intervention to mitigate suicide risk. Cognitive and Behavioral Practice, 19(2): 256-264. [Link]

Tarrier, N., Taylor, K., \& Gooding, P. (2008). Cognitivebehavioral interventions to reduce suicide behavior: a systematic review and meta-analysis. Behavior modification, 32(1), 77-108. [Link]

Wetherall, K., Robb, K. A., \& O'Connor, R. C. (2019). Social rank theory of depression: A systematic review of self-perceptions of social rank and their relationship with depressive symptoms and suicide risk. Journal of affective disorders, 246, 300-319. [Link]

Yen, S., Spirito, A., Weinstock, L. M., Tezanos, K., Kolobaric, A., \& Miller, I. (2019). Coping long term with active suicide in adolescents: Results from a pilot randomized controlled trial. Clinical child psychology and psychiatry, 24(4): 847-859. [Link]

Ziaei, R., Viitasara, E., Soares, J., Sadeghi-Bazarghani, H., Dastgiri, S., Zeinalzadeh, A. H. Mohammadi, R. (2017). Suicidal ideation and its correlates among high school students in Iran: a cross-sectional study. BMC psychiatry, 17(1): 147. [Link] 